\title{
Análisis histórico y primeras documentaciones de los japonesismos bélicos y gubernamentales en el español actual
}

\author{
Rafael Fernández Mata ${ }^{1}$ \\ Universidad de Córdoba, España
}

\begin{abstract}
Resumen
Por primera vez en la lexicología española, con el presente texto se pretende aportar nueva información y conclusiones acerca de la historia de los japonesismos -o voces tomadas en préstamo de la lengua japonesarelacionados con la guerra y el gobierno. En primer lugar, se expondrá un listado de japonesismos usados en el español de hoy (considerados estos desde una perspectiva panhispánica) y el método mediante el cual se ha conseguido dicho catálogo. En el segundo apartado, primero se explicarán los datos históricos que serán tomados en cuenta para describir las voces $\mathrm{y}$, seguidamente, se realizará un análisis histórico y exhaustivo de 10 ítems léxicos. Por último, dividiremos las conclusiones de acuerdo con diferentes aspectos: etimología, aceptación por la RAE, etc.

Palabras clave: japonesismo, japonesismos de la guerra y el gobierno, historia de la lengua española, lexicografía, lexicología, Diccionario de la lengua española.
\end{abstract}

1 Para correspondencia, dirigirse a: Rafael Fernández Mata (L42femar@uco.es / rafaelfernandezmata@gmail.com). Profesor Ayudante Doctor, Universidad de Córdoba (España), +34 625798141 . 


\title{
HisTORICAL ANALYSIS AND FIRST DOCUMENTATIONS OF JAPANESE LOANWORDS FOR WAR AND GOVERNMENT IN CURRENT SPANISH
}

\begin{abstract}
This essay aims at exploring and contextualising a phenomenon of Spanish Lexicology, the study of which remains incomprehensive: japonesismos, or terms borrowed from the Japanese language. The scope of this text will limit itself to terminology related to War \& Government. First, a compilation of Japanese loanwords that can be found in current Spanish (approaching the language from a unifying perspective) will be elaborated. In addition, the specific methodology employed to identify and compile said inventory of loanwords will be presented. In continuation, the consideration of relevant historical data regarding the contextualisation of these loanwords will be realized in order to provide an exhaustive historical analysis of 10 lexical items. Finally, maintaining a wider perspective of the historical study of Japanese loanwords, the conclusions derived from each term will organized and described.
\end{abstract}

Keywords: Japonesismo, Japanese loanwords for War \& Government, History of Spanish language, Lexicography, Lexicology, Diccionario de la lengua española.

Recibido: $20 / 03 / 20$

Aceptado: 04/09/20

\section{INTRODUCCIÓN}

Debido a la interdisciplinaridad que rige el mundo científico actual, el número de expertos e investigaciones que integran diferentes metodologías y ramas del saber es cada vez mayor. Este fenómeno ha beneficiado sobremanera a las ciencias lingüísticas; en nuestro caso, la lexicología y la lexicografía.

Como resultado de esta perspectiva ecléctica y unificadora, quisimos analizar las palabras tomadas en préstamo de la lengua japonesa. El deseo de explorar un terreno prácticamente desconocido por la filología hispánica dio lugar a la publicación de una tesis y más de una veintena de artículos. Este en concreto se inscribe en la estela de nuestros trabajos anteriores y su objetivo no es otro sino el de actualizar datos ya publicados (Fernández Mata, 2015b, 2017, 2018b) y aportar nueva información y conclusiones acerca de la historia de cada una de estas voces procedentes de la lengua japonesa.

A continuación, pasaremos a explicar brevemente los apartados en que se divide y el propósito de cada uno de ellos: 
(1) Como su propio nombre indica, en el primer epígrafe, además de exponer la lista de japonesismos utilizados en el español de hoy (pensado desde una visión panhispánica), resumiremos brevemente el método o proceso con que los reunimos.

(2) En la segunda sección, realizaremos un análisis histórico y exhaustivo de 10 ítems léxicos: «banzay», «busido», «camicace», «catana», «daimio», «jaraquiri», «micado», «samuray», «siogun» y «taicun». Explicaremos qué datos históricos tomaremos en cuenta para describir dichas voces y cómo quedará organizada la información.

(3) En el último apartado expondremos nuestras conclusiones.

\section{INVENTARIO DE JAPONESISMOS EN LA LENGUA ESPAÑOLA ACTUAL ${ }^{2}$}

Las fuentes a las que recurrimos para conseguir este repertorio de japonesismos se pueden distribuir en torno a dos grupos: de un lado, buscadores en línea, y, por otro, diccionarios de la lengua española actual:

\subsection{Portales CIBERnÉTICOS}

Iniciamos la investigación en Google (www.google.es), Academia.edu (http://www.academia.edu/), Infoling (www.infoling.org), la Biblioteca Virtual Miguel de Cervantes (http://www.cervantesvirtual.com/) y el portal de búsqueda de Dialnet (http://dialnet.unirioja.es/). Nuestra intención era recabar posibles sitios web, artículos, tesis o trabajos en los que se ofreciera un corpus de japonesismos utilizados en español actual.

A los datos compilados les sumamos los listados de los diccionarios que mencionamos a continuación.

\subsection{NUEVE OBRAS LEXICOGRÁFICAS DEL ESPAÑOL MODERNO}

Estos diccionarios son: el Diccionario de voces de uso actual (DVUA) (1994), el Diccionario del español actual (DEA) (1999), la vigesimosegunda edición 
del Diccionario de la lengua española (DLE 2001) (2001) -consultada en línea-, el Diccionario de uso del español de América y España (DUEAE) (2003) -formato CD-ROM-, el Nuevo diccionario de voces de uso actual (NDVUA) (2003), el Gran diccionario de uso del español actual (GDUEA) (2006) -formato CD-ROM-, el Diccionario de uso del español (DUE) (2008) -formato CD-ROM, basado en la tercera edición en papel de 2007-, el Diccionario Clave: diccionario de uso del español actual (DClave) -versión en línea-y la versión en línea de la vigesimotercera edición del Diccionario de la lengua española (DLE 2014) (2014 y posteriores actualizaciones).

El proceso de búsqueda requirió una retroalimentación constante ${ }^{3}$, la eliminación de voces repetidas y un rastreo minucioso en las obras en papel. Sumados todos los ítems léxicos descubiertos y eliminadas las voces repetidas o de procedencia no japonesa ${ }^{4}$, obtuvimos un catálogo de 148 japonesismos. Aplicamos una serie de filtros -(i) uso muy circunstancial o ausencia de las voces en los corpus del español o en las obras lexicográficas descritas; (ii) lexemas derivados, aquellos que resultaron de la unión de una lexía japonesa y un elemento compositivo español o foráneo (antepuesto o pospuesto $)^{5}$; (iii) eliminación de dobletes ${ }^{6}$ - para tamizar los resultados y nuestro catálogo se redujo a 92 japonesismos ${ }^{7}$ :

3 Debida, por una parte, a que los motores de búsqueda de las obras lexicográficas eran defectuosos (Cf. Fernández Mata, 2016a) y, por otra, a que descubríamos japonesismos en otras fuentes. Esto nos obligaba a regresar a las fuentes ya analizadas para comprobar si contenían la voz recién encontrada.

4 Los vocablos feng-sui y tai-chi.

5 Únicamente hicimos una excepción con las voces «sintoísmo» y «toquiota», puesto que la voz originaria de la que procede la primera - «sinto»- prácticamente ha caído en desuso y, en relación con la segunda, uno de sus constituyentes es necesario en nuestro idioma para formar los gentilicios.

6 De los dobletes «catán»-«catana», «ninyusu»-«ninyisu»y «quimón»-«quimono», resolvimos que solo emplearíamos los significantes: «catana», «ninyusu» y «quimono». Por cuestión de espacio, no podemos incluir en el artículo los motivos histórico-lingüísticos que nos han llevado a elegir la solución «catana», «quimono» y «ninyusu» (Cf. Fernández Mata, $2015 \mathrm{a}, 2019 \mathrm{~b}$ y $2019 \mathrm{~d}$ respectivamente para hallar respuesta).

7 Estos quedan representados gráficamente siguiendo nuestro método de transcripción (Cf. Fernández Mata, 2018c). A excepción de las referencias bibliográficas (que se transcriben tal cual han sido publicadas) y de los elementos de origen japonés en citas textuales, a lo largo de nuestro artículo adaptaremos los japonesismos con nuestro patrón. Por este motivo, puede resultar extraño a los lectores que utilicemos Toquio -en lugar de Tokio-para la capital nipona o Meyi -y no Meiji- cuando nos referimos al periodo histórico. 


\begin{tabular}{|c|c|c|c|c|}
\hline \multicolumn{5}{|c|}{ Corpus de japonesismos actuales [92] } \\
\hline «aiquido» & «catacana» & «manga» & «saionaras» & «tanca» \\
\hline «aiquidoca» & «catana» & «maque» & «samuray» & «tatami» \\
\hline 《anime» & «cen» & «maquisusi»» & «saque» & «tempura» \\
\hline «banzay» & «coto» & «micado» & «sasimi»» & «tepaniaqui» \\
\hline 《biombo» & «daimio» & «misubisi» & «sen» & «teriiaqui»» \\
\hline 《bonsay» & «dan» & «moxa» & «siamisén» & «tofu» \\
\hline 《bonzo» & «doyo» & «ninya» & «siasu» & «toiota» \\
\hline 《busido» & «futón» & «ninyusu» & «sintoísmo» & «toquiota» \\
\hline 《butó» & «guesia»» & «nipón» & «siogun» & «uasabi» \\
\hline «cabuqui»» & «iaquitori» & «nori»» & «Siso» & «umami» \\
\hline «caicen» & «ien» & «nunchaco» & «soja» & «yinco» \\
\hline «camicace» & «ipon» & «obi»» & «sudocu» & «yudo» \\
\hline «canyi» & «iquebana» & «origami» & «sumo»» & «yudoca» \\
\hline «caquemono» & «iucata» & «otacu» & «sunami» & «yudogui»» \\
\hline «caqui» & «jaicay» & «poquemon» & «suquiiaqui» & «yuyusu» \\
\hline «caraoque» & «jaicú»» & «quendo» & «surimi»» & «zacén» \\
\hline 《carate» & «jaraquiri» & «querin» & «susi» & \\
\hline 《carateca» & «jentay» & «quimono» & «taicun» & \\
\hline 《catá» & «jiragana» & «(requi»» & «tamagochi»» & \\
\hline
\end{tabular}

En el inventario recién expuesto hemos ensombrecido las 10 voces relativas a la guerra y el gobierno (Fernández Mata, 2018b). Desde el punto de vista de una clasificación semántica, estas 10 unidades constituyen el tercer mayor número de palabras procedentes de la lengua japonesa (Fernández Mata, 2017: 161).

\section{ESTUDIO HISTÓRICO DE LOS JAPONESISMOS BÉLICOS Y GUBERNAMENTALES}

Son numerosas las interrogantes que se nos plantean a la hora de abordar la historia de cualquier préstamo lingüístico: ¿Cuándo se produjo su introducción y por qué? ¿Cuándo se registró por primera vez? ¿Qué fuentes se deben utilizar para iniciar la búsqueda de las primeras documentaciones? ¿Dejó de usarse un japonesismo durante algún tiempo? ¿Se ha intentado insertar la voz extranjera en diferentes etapas de nuestra lengua? ¿Intermedió alguna otra lengua en el proceso de adopción? ¿La coincidencia formal entre el significante español y el étimo es elevada o sufrió alguna deturpación durante el proceso de adopción? ¿A qué se debió esa modificación formal? 
¿Qué diccionario hispánico introdujo por primera vez un descriptor etimológico completo?

Nuestro análisis tratará de despejar tales incógnitas y de rectificar/ actualizar algunos datos anteriormente publicados ${ }^{8}$. Si bien, antes de pasar al examen diacrónico de cada una de las voces, nos detendremos para explicar la metodología que hemos seguido.

\subsection{Metodología}

A fin de obtener el mayor número de datos existentes sobre un determinado japonesismo, hemos adoptado una metodología ecléctica, deductiva y con una retroalimentación constante. El listado de los 10 ítems ha sido sometido al mismo proceso: en primer lugar, hemos extraído toda la información que arrojaban las siguientes fuentes en lengua española (diccionarios, corpus y hemeroteca):

- Diccionarios históricos de la lengua española: el Diccionario crítico etimológico castellano e hispánico (DCECH) y el Nuevo tesoro lexicográfico de la lengua española (NTLLE).

- Diccionarios del español actual (cualquier información histórica): el DVUA, el DEA, el DLE 2001, el GDUEA, el DUEAE, el NDVUA, el DUE, el DClave y el DLE 2014.

- Los corpus de la lengua española: el Corpus diacrónico del español (CORDE), el Corpus diacrónico y diatópico del español de América (CORDIAM), el Corpus de referencia del español actual (CREA) y el Corpus del español del siglo XXI (CORPES XXI).

- La Hemeroteca digital (Hemeroteca) de la Biblioteca Nacional de España. Para ampliar nuestras pesquisas, hemos considerado asimismo las descripciones aportadas por otras lenguas próximas a la española (diccionarios y corpus) que contaban con el japonesismo en cuestión:

- Diccionarios del inglés: el Merriam-Webster's Collegiate Dictionary (MWCD) y el Oxford English Dictionary (OED).

- Diccionarios del francés: el Dictionnaire de français Larousse (DFL), Le Petit Robert de la langue française (PR), el TLFi: Trésor de la langue française informatisé (Trésor), el Dictionnaire historique de la langue française (DHLF) y el Grand Dictionnaire universel du XIX $X^{e}$ siècle (GDU XIX).

\footnotetext{
8 A lo largo de nuestras publicaciones ya advertíamos de que podríamos descubrir informaciones que contradijeran o invalidaran algunas de nuestras suposiciones.
} 
- Diccionarios del portugués: el Dicionário Houaiss da Língua Portuguesa (DHLP) y el Dicionário Priberam da Lingua Portuguesa (DPLP).

- Corpus diacrónico del portugués: Corpus Lexicográfico do Português.

- El Glossário luso-asiático de Dalgado (1919-1921).

- Diccionarios del italiano: Il Devoto-Oli: vocabolario della lingua italiana (DOVLI), lo Zingarelli 2015. Vocabolario della lingua italiana (Zingarelli) y el Dizionario etimologico della lingua italiana (DELI).

También hemos contado, como no podía ser de otro modo, con la información histórica que arrojaba un diccionario monolingüe japonés en línea: el Daiyirin $<$ 大辞.

En último lugar, pero no menos importante, consideraremos los valiosos datos de la tesis de Colby Knowlton (1959) y del artículo de Prieto (2007).

Lamentablemente, en la gran mayoría de los casos, nuestra investigación se detenía en las fuentes anteriores; pero, en otras ocasiones, se hacía referencia a materiales concretos donde pudimos localizar datos interesantes con que llevar a cabo una descripción más profunda. Gracias a la retroalimentación, pudimos ampliar no solo el conjunto de materiales utilizados, sino el contenido de estos.

Con respecto a la explicación histórica, esta se ha organizado en tablas. Cada japonesismo, ordenado alfabéticamente, cuenta con una tablacompendio similar a la que a continuación se expone:

\begin{tabular}{|l|c|l|}
\hline \multicolumn{3}{|c|}{ «PALABRA»/pa'labra/ } \\
\hline 1. ${ }^{\text {doc. } \text { textual }}$ & palabra & Fecha: Fuente \\
\hline 1. doc. lexicográfica & palabra & Fecha: Fuente \\
\hline \multicolumn{3}{|c|}{ Descripción histórica } \\
\hline
\end{tabular}

En la parte superior indicamos la voz analizada. Tanto la adaptación gráfica al alfabeto latino como su representación fonológica -con AFI- responden a nuestro método de transcripción (Fernández Mata, 2018c).

A continuación, se incluyen los registros textuales y lexicográficos que inauguran la recepción del japonesismo. Para la primera documentación textual de una voz hemos recurrido a los corpus del español, presentes (CORPES XXI y CREA) y pretéritos (CORDE y CORDIAM), a la Hemeroteca y a otras posibles fuentes específicas -en caso de que las fuentes lexicográficas ofrezcan alguna pista-. En la columna central, antes de la fecha y la fuente, hemos indicado la forma exacta (en redonda o cursiva, mayúscula o minúscula, con comillas o sin comillas, etc.) mediante la que se transcribe el japonesismo en su primera aparición textual y lexicográfica. Por lo que respecta a la primera vez que se incluye una voz en un diccionario 
del español, hemos usado, en primera instancia, los datos del DCECH y el NTLLE. En ausencia de información, hemos rastreado en los diccionarios del español moderno: DVUA, DEA, DLE 2001, GDUEA, DUEAE, NDVUA, DUE, DClave y DLE 2014.

En la parte inferior, historia de la palabra, hemos descrito con detalle estos aspectos: (i) época o épocas de la historia del español en las que se introdujo la palabra; (ii) posibles intentos de trasplante en nuestra lengua y periodos en los que la voz no fue usada; (iii) lenguas intermediarias entre el resultado español y el étimo japonés; (iv) causas -lingüísticas y extralingüísticas- de las diferencias formales entre la adaptación española y la japonesa ${ }^{9}$. En esta sección, además de las fuentes anteriores, hemos consultado toda la información disponible en diccionarios y corpus de otras lenguas (inglés, francés, italiano, portugués y japonés), así como materiales específicos escritos en dichos idiomas.

Otra característica fundamental que debe ser considerada en nuestras fichas descriptivas es la manera en que hemos adaptado gráficamente los japonesismos. A lo largo de todas nuestras investigaciones hemos escrito las voces de origen japonés utilizando nuestro método de transcripción (Cf. Fernández Mata, 2018c), mediante el cual el vocablo aparece entre comillas bajas (《»)). Esta elección nos permitía, por un lado, distinguir en el texto la unidad a la que hacíamos referencia de sus posibles variantes gráficas -la gran mayoría adaptadas con un patrón extranjerizante del que hablaremos más adelante-, por otro, ponía en práctica el método que habíamos desarrollado. A diferencia de anteriores trabajos, en esta ocasión no hemos usado la cursiva para indicar que un determinado japonesismo es un mero extranjerismo por los siguientes motivos: (1) hemos intentado preservar el valor original que se le dio en el texto donde se documenta (esto quiere decir que, de emplearse la cursiva, se mantienen los matices

9 Pese a que estas cuestiones se tratarán en profundidad en la sección de conclusiones, previa lectura de las tablas, es necesario prevenir de los siguientes puntos: (i) siempre que califiquemos una grafía, por ejemplo $k$, como extranjerizante, exótica o foránea, nos estamos refiriendo al hecho de que el japonesismo ha sido adaptado al alfabeto latino mediante un patrón gráfico impropio de la lengua española; (ii) tras nuestro análisis histórico, hemos resuelto que ni los argumentos cronológicos (como primeras documentaciones) ni las justificaciones transcriptivas (como el sistema Hepburn) son suficientes para determinar que otra lengua ha actuado como intermediadora entre el japonés y la adaptación hispánica; estas pruebas se han de combinar con hechos socioculturales paralingüísticos y con la intención de los usuarios en esas primeras documentaciones. De este modo, cuando usemos oraciones del tipo No existen razones fehacientes para creer que esta voz se adoptara a través de una lengua intermediaria, lo que pretendemos transmitir es que no existen argumentos histórico-culturales ni pragmáticos para señalar la intermediación de otra lengua. 
del autor primitivo); (2) puesto que hemos ofrecido transcripciones de los japonesismos en diversas lenguas, quisimos evitar la confusión del lector, esto es, que creyera que un determinado japonesismo se escribía en cursiva, por ejemplo, en inglés. Relacionado con lo recién expuesto, tampoco hemos utilizado la cursiva con función metalingüística ${ }^{10}$, dado que así hemos salvado nuestro tex to de posibles malinterpretaciones. En definitiva, cuando transcribimos los japonesismos, no empleamos la cursiva ni con valor metalingüístico ni para indicar su estado de adopción ${ }^{11}$.

\subsection{ANÁLISIS DE LOS 10 ÍTEMS LÉXICOS}

\begin{tabular}{|c|c|c|}
\hline \multicolumn{3}{|c|}{ «BANZAY»/baN'sai/ o /baN'Aai/ } \\
\hline $1{ }^{\text {a }}$ doc. textual & $\begin{array}{l}\text { ¡Banzai! } \\
\text { ¡banzay! }\end{array}$ & $\begin{array}{l}\text { 23/04/1904: La Hormiga de oro } \\
\text { 03/12/1914: El Imparcial (Madrid) }\end{array}$ \\
\hline 1. ${ }^{a}$ doc. lexicográfica & banzai & 2012: DClave \\
\hline $\begin{array}{l}\text { Probablemente por su } \\
\text { por millón en CORPE } \\
\text { banzay-), «banzay»n } \\
\text { hispánicas utilizadas e } \\
\text { el momento, el primer } \\
\text { cual aconseja que deb } \\
\text { gráfica por tratarse de } \\
\text { del término, no aporta } \\
\text { no ha sido jamás estu } \\
\text { morfología, dado que } \\
\text { adoptada de la lengua } \\
\text { 2017)-, es de esperar qu } \\
\text { comprobamos en COR } \\
\text { interiectiva nos hizo }\end{array}$ & $\begin{array}{l}\text { empleo ca } \\
\text { XXI y CF } \\
\text { ica ha sido } \\
\text { este estudi } \\
\text { diccionario } \\
\text { ser transc } \\
\text { n extranjer } \\
\text { hayor infor } \\
\text { liado por } 1 \\
\text { ertenece a 1 } \\
\text { tponesa }(v i \\
\text { su ocurren } \\
\text { ES XXI y } \\
\text { ensar que, }\end{array}$ & $\begin{array}{l}\text { i marginal o circunstancial ( } 0.01 \text { casos } \\
\text { EA -para la grafía banzai; no se registra } \\
\text { inventariado por las obras lexicográficas } \\
\text { (Cf. además DCECH y NTLLE). Hasta } \\
\text { en incluir esta voz ha sido el DClave, el } \\
\text { ito en cursiva o con otra diferenciación } \\
\text { smo. Aparte de aclarar el origen japonés } \\
\text { nación etimológica }{ }^{12} \text {. Este aspecto, pues, } \\
\text { lexicografía hispánica. Volviendo a su } \\
\text { categoría de las interjecciones -la única } \\
\text { l. Prieto, 2007; Fernández Mata, } 2015 b \text { y } \\
\text { cia en español sea bastante inusual }{ }^{13} \text {, como } \\
\text { CREA. Asimismo, a priori, su naturaleza } \\
\text { en su práctica totalidad. la voz debería }\end{array}$ \\
\hline
\end{tabular}

10 En su lugar, hemos transcrito el japonesismo según nuestro método, esto es, entre comillas bajas («»).

11 Según la nueva ortografía (RAE y ASALE, 2010: 601), los extranjerismos crudos o no adaptados "deben escribirse siempre en los textos españoles con una marca gráfica que destaque su condición de palabras pertenecientes a otra lengua: preferentemente en cursiva en la escritura tipográfica [...] y entre comillas en los textos manuscritos".

12 Nosotros informamos acerca de esto en Fernández Mata (2016a).

13 Aunque las Academias (2009) no aporten datos sobre la frecuencia de uso de esta categoría léxica, cualquier hablante nativo podría intuir que esta no es muy elevada, máxime en nuestro caso, puesto que «banzay» está determinada por un contexto muy exclusivo. 
estar introducida por verbos de decir; sin embargo, los ejemplos de la Hemeroteca demuestran que rápidamente se adaptó y adquirió nuevos usos morfológicos en la lengua española, puesto que funciona en muchas ocasiones como núcleo sustantivo o como complemento de un grupo nominal cuyo núcleo es grito/s o formas verbales relacionadas con gritar. Por otro lado, recuérdese que el carácter expresivo inherente a las interjecciones ${ }^{14}$ provoca que desde su primer registro se emplee entre signos de exclamación en casi todas las ocasiones: "Cantos guerreros, himno nacional japonés, gritos de ¡Banzai! ¡banzai! (¡viva! japonés)” (La Hormiga de oro, España, 23/04/1904); "Los banzais (hurras japoneses) atronaban el espacio" (La Época, Madrid, 26/08/1904); "Y de cuando en cuando rasga los aires el ¡banzai! que lanzan miles de bocas” (Pluma y lápiz, Barcelona, 28/08/1904); "Una parte de los nipones se rindió, pero los demás prefirieron seguir luchando hasta que fueron exterminados y murieron lanzando su famoso grito: «Banzai»” (El Imparcial, Madrid, 02/09/1904); "á lo que responden las avanzadas japonesas con el grito de ¡Banzai! y cantando el himno nacional japonés" (La Correspondencia de España, 29/09/1904); “Los japoneses se precipitaron hacia la cúspide del cerro gritando ¡Banzai!” (El Imparcial, Madrid, 02/12/1904); “el Losque se convirtió en enjambre de infantería que, al grito de ¡banzay!, asaltó las trincheras á la bayoneta y se apoderó de la posición” (El Imparcial, España, 1914); "y muere al grito de «TENNUYICA BANZAY ${ }^{15}$ » «Por el Emperador. Adelante»" (Diario de avisos, Santa Cruz de La Palma, 10/12/1937). En las primeras documentaciones de 1904, el extranjerismo está acompañado con marcas autonímicas, traducciones o explicaciones perifrásticas, pero nos sorprende que solo dos días más tarde desde la última el vocablo aparezca con el calificativo famoso grito, lo cual podría ser síntoma de la vertiginosa aceptación de esta unidad. En efecto, el contexto histórico (nos referimos al conflicto ruso-japonés de 1904-1905, vid. Junqueras, Madrid y Martínez 2013; Hane 2015; Walker 2017) favoreció, sin duda, la propagación de la voz. Los testimonios arriba expuestos son extractos de noticias que narraban aquella situación bélica. No ocurrió así con otras lenguas, en las que el japonesismo se documenta en la década anterior: 1892 (MWCD) o 1893 (OED) en lengua inglesa; 1897 en portugués (Dalgado 1919-1921); 1898 en italiano (Zingarelli); solo el francés parece compartir nuestra fecha de entrada (1904, según Colby Knowlton 1959) ${ }^{16}$.

14 Así lo precisa la gramática actual: "La interjección es una clase de palabras que se especializa en la formación de enunciados exclamativos" (RAE y ASALE 2009: 2479).

15 No es la primera vez que se emplea la expresión completa en japonés y su traducción en lengua española, pues, gracias al CORDE, sabemos que José María Gironella, en su libro de 1964 El Japón y su duende, escribe: "Tenno heika banzai. "¡Mil años viva el emperador!””.

16 En Colby Knowlton (1959: 482-483) leemos que en su primer uso (1904) se transcribió Bauzai!, mientras que en otro ejemplo de 1908 ya se localiza Banzai. Llama la atención que en esta segunda documentación, el japonesismo aparezca con la siguiente estructura: "aux cris 
Por lo que respecta a su adaptación gráfica, no se siguen los parámetros transcriptivos propuestos por la ortografía de la RAE de 1820, la cual estaba vigente en la época en que se produjo la adopción. Según esta, el diptongo /'ai/ a final de palabra no podía escribirse con $i$ latina, esto es, ai, sino $a y^{17}$. Por el momento, parece que la cultura inglesa fue la impulsora de tal significante escrito, pues los primeros registros textuales - no solo de la voz, sino también de la combinación-se atestiguan en inglés ${ }^{18}$.

\begin{tabular}{|l|c|l|}
\hline \multicolumn{3}{|c|}{ «BUSIDO»/bu'sido/ } \\
\hline 1. $^{\text {a doc. textual }}$ & iBushido! & 07/02/1904: El Álbum ibero americano \\
\hline 1. $^{\text {a doc. lexicográfica }}$ & bushido & 1999: DEA \\
\hline $\begin{array}{l}\text { Hasta el DLE 2001 (con la grafía en cursiva, bushido, también en DLE 2014), } \\
\text { la RAE no había incluido este japonesismo en ninguna de sus obras (DCECH } \\
\text { y NTLLE). El primer diccionario hispánico en catalogar esta voz fue el DEA. } \\
\text { Ninguna de estas obras aporta mayor información etimológica que la de su } \\
\text { origen japonés, es decir, no incluyen el étimo. En cuanto a su documentación } \\
\text { textual, ni el CORDE ni el CORDIAM ofrecen datos al respecto, }\end{array}$
\end{tabular}

de Banzai”, esto es, “a los gritos de «banzay»”. Esta construcción análoga a la española lleva a plantearnos las mismas interrogantes que en otras de nuestras investigaciones (Fernández Mata 2020a y 2020b): ¿Quién copió a quién? ¿No pudieron llegar ambas lenguas a la misma solución por tener un sustrato latino común? La situación se complica al entrar en juego la lengua inglesa y la lengua portuguesa, puesto que documentamos dos casos anteriores en los que observamos construcciones similares: "At the departure of the Imperial train, the citizens raise loyal cries of 'banzai! banzai!"'(1893: OED); "Aproveitam-se avidamente os minimos pretextos, aqui nas ciudades como alem nas aldeias, para pomposas glorificações; e o grito -banzai!- freme entre a turba" (1897: Dalgado 1919-1921). La cronología sugiere que la lengua inglesa intermedió entre el étimo japonés y otras lenguas europeas (primero en portugués, 1897, y luego en francés, 1908, y español, 1914). ¿Nuestra combinación podría ser un calco/imitación de la inglesa?

17 Queda demostrado en los siguientes extractos:

"Ocupa la y consonante el lugar de la i vocal en las voces que terminan con ella sin acento agudo, como en hay, ley, Rey, doy, estoy, muy; pero cuando cargare el acento en la i se usará de la vocal, como en maravedí, baharí, y en los pretéritos perfectos de algunos verbos, como reí, leí, caí, ví, oí, escribí” (RAE 1820: 57-58);

"Los diptongos que tenemos en nuestra lengua son los diez y seis que se notan en estos egemplos: ai ó ay, en dabais, hay" (RAE 1820: 62);

"Adviértese que irán sin acento alguno las voces acabadas en y, las cuales todas forman diptongo, como estay, Muley, convoy, por tener siempre larga la última sílaba" (RAE 1820: 84-85).

18 Consideramos, además, que en el sistema anglosajón desarrollado por Hepburn la combinación /ai/ se transcribe como ai. Así, leemos en Hepburn (desde la primera edición de su diccionario, 1867, hasta la versión que acabó por imponerse, la tercera, de 1886): “ai has the sound of ai in aisle, or like eye". 
pero sí el CREA, que fecha su primera aparición en 1980 (bushido, España). Sin embargo, gracias a la Hemeroteca, podemos ubicar sus primeros registros en 1904, año desde el cual se documenta esta voz ininterrumpidamente hasta 2019, en casi todos los casos empleada en textos de temática bélica. En inglés su primer testimonio hemos de situarlo unos años antes: 1898 (MWCD y OED). Ninguna de las obras italianas, francesas o portuguesas manejadas nos informa acerca de la primera documentación de esta $\mathrm{voz}^{19}$. Podemos suplir esta falta de información gracias a la tesis de Colby Knowlton (1959: 495): "These words [se refiere a bushi y Bushido] seem to have come into international use chiefly as a result of the widespread knowledge of the book first written in English by Inazo Nitobe (1862-1933) and published in Philadelphia in 1898. Later the work, entitled Bushido, was translated into other languages". Según la tesis de Rodríguez (2007: 170-171), la primera traducción de la obra de Nitobe en lengua española se produjo en 1909 de la mano de Gonzalo Jiménez de la Espada, titulada Bushido. El Alma de Japón. En cuanto a las primeras documentaciones en francés, portugués e italiano, Colby Knowlton (1959: 495) localiza las voces en textos de 1924, 1932 y 1939 respectivamente. Además de la repercusión que tuvo dicha obra, creemos que también actuó como difusor internacional el conflicto bélico entre Rusia y Japón (1904-1905). Por lo concerniente a su adaptación gráfica, no hay lugar a dudas, se ha empleado un sistema de transcripción extranjerizante ${ }^{20}$, pues el dígrafo inglés $s h$ ha dado lugar a que esta voz cuente con dos pronunciaciones en español actual: la anglo-nipona, esto es, se articula un sonido consonántico, prepalatal, fricativo, oral, sordo, [J] (DEA), o la propia hispánica, /s/. A causa del dígrafo $s h$ y de su patrón acentual llano (DEA), es muy probable que la vía de entrada de esta palabra haya sido a través de la escritura, desde la lengua inglesa, pues las anotaciones fonéticas de los diccionarios MWCD y OED demuestran que en inglés se imitó fielmente el patrón acentual del japonés, proparoxítono. Al leerla, el hablante de español medio tendía a la realización paroxítona del término, debido a que este es el patrón acentual preferido en nuestra lengua ${ }^{21}$ y porque en lengua inglesa no existen marcas gráficas para indicar la tonicidad. Para evitar dobletes articulatorios, nuestro sistema de transcripción emplea «busido», solución que mejor respeta nuestro sistema ortotipográfico.

19 Únicamente el DHLP añade la imprecisa fecha de siglo XX para la lengua portuguesa.

20 Casi con total seguridad, el Hepburn, ya que en las anotaciones de sus diccionarios explica que la grafía sh: "has the sound of sh in shall, ship" (primera edición de 1867) o "is pronounced like sh in shall, ship, shop" (tercera edición de 1886). Esta grafía es la utilizada por todas las obras lexicográficas extranjeras que la recogen (MWCD, OED, DFL, DHLP y Zingarelli).

21 Tratamos esta característica en otros trabajos (Fernández Mata 2015b y 2017): es muy común que los japonesismos se adapten al patrón acentual prototípico de la lengua española, el paroxítono (Lapesa 2005; Quilis 2006; RAE y ASALE 2011). 


\begin{tabular}{|c|c|c|}
\hline \multicolumn{3}{|c|}{ 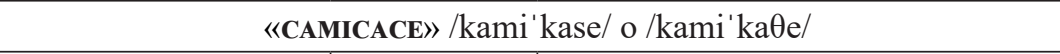 } \\
\hline xtual & $\begin{array}{l}\text { "Kamikaze" } \\
\text { Kamikace } \\
\text { «camicace» }\end{array}$ & $\begin{array}{l}\text { 21/05/1937: Falange (Las Palmas de } \\
\text { Gran Canaria) } \\
\text { 09/07/1964: Marca (Madrid) } \\
\text { 25/04/1979: El Mundo deportivo } \\
\text { (Barcelona) }\end{array}$ \\
\hline ográfica & camicace & 1992: DLI \\
\hline $\begin{array}{l}\text { japonés kamikaze, vi } \\
\text { término se usó origir } \\
\text { el siglo XIII destruy } \\
\text { el país. OED, DELI } \\
\text { una noche de agosto } \\
\text { typhons qui ont détr } \\
\text { Nosotros estamos de } \\
\text { Kase (2005: 13): "E } \\
\text { al siglo XIII, cuand } \\
\text { las fuerzas aliadas de } \\
\text { en } 1281 \text { pero fracasa } \\
\text { por lo que, según pa } \\
\text { dioses"; y por Prieto } \\
\text { Japón en los años } 1 \\
\text { producía una invasió } \\
\text { intervención de la } \\
\text { decisivamente a la } \\
\text { creencia de que era } \\
\text { como hemos tenido } \\
\text { y en los datos de la } \\
\text { 2001, GDUEA, DU } \\
\text { (MWCD, OED, DF } \\
\text { Zingarelli), procede } \\
\text { en la Segunda Guer } \\
\text { aviones cargados de } \\
\text { 98) informan de cu } \\
\text { “Todavía no se había } \\
\text { ficializadoeste tin }\end{array}$ & $\begin{array}{l}\text { a vez esta } \\
\text { ace, con e } \\
\text { ivino" } 22 \text { ( } \\
\text { iente en ja } \\
\text { a flota mo } \\
\text { LP concre }\end{array}$ & $\begin{array}{l}\text { en una de sus obras lexicográficas en } \\
\text { uiente descriptor etimológico: "Del } \\
\text { LE). Según DUEAE y Daiyirín, este } \\
\text { ss para referirse a dos tifones que en } \\
\text { 1, la cual tenía intención de invadir } \\
\text { que este hecho histórico tuvo lugar } \\
\text { F corrige que "ce mot désigne deux } \\
\text { on mongole en } 1274 \text { et en } 1281 \text { "23. } \\
\text { dea, también propuesta por Axell y } \\
\text { xaze» («Viento divino») se remonta } \\
\text { goles de Kublai Khan -en realidad } \\
\text { intentaron invadir Japón en } 1274 \text { y } \\
\text { fo las dos flotas en ambas ocasiones } \\
\text { fones o kamikazes enviados por los } \\
\text { blicos a sendos tifones que azotaron } \\
\text { edentes de China. Esta providencial } \\
\text { nbos acontecimientos contribuyó } \\
\text { ores y alentó entre los japoneses la } \\
\text { o de los dioses". El uso moderno, } \\
\text { ar en las primeras documentaciones } \\
\text { as hispánicas (DVUA, DEA, DLE } \\
\text { E, DClave, DLE } 2014 \text { ) y extranjeras } \\
\text { or, DHLP, DPLP, DELI, DOVLI, } \\
\text {-suicida de los aviadores japoneses } \\
945 \text { ), que consistía en estrellar sus } \\
\text { flota enemiga. Axell y Kase (2005: } \\
\text { mer ataque "camicace» no oficial: } \\
\text { de la palabra kamikaze ni se había } \\
\text { el teniente Fusata Iida, al mando de }\end{array}$ \\
\hline
\end{tabular}

22 Como ya analizamos en Fernández Mata (2016a), el descriptor no aclara qué parte del étimo, kamikaze, significa 'viento' y qué parte, 'divino'.

23 Fechas que también recoge el Trésor. 
proteger a los bombarderos y torpederos en la segunda tanda de ataques en Pearl Harbour, el 7 de diciembre de 1941, fue realmente el primer kamikaze". No obstante, el grueso de ataques tuvo lugar desde el otoño de 1944 -la primera misión suicida de la guerra que fue aprobada oficialmente se fecha el 25 de octubre de 1944- hasta principios del verano de 1945 (Axell y Kase 2005: 84, 100; Hill 2006: 1; DFL y PR). Hasta ese periodo, "las tácticas suicidas se habían utilizado como último recurso, por ejemplo cuando un avión estaba dañado y el piloto tenía que decidir si abandonar la nave y arriesgarse a ser capturado o estrellarse contra un barco o avión enemigo. Eran las decisiones imprevistas, personales, de unos hombres mentalmente preparados para morir según la tradición del Bushido. Desde mediados de 1942, hubo casos de pilotos, tanto japoneses como estadounidenses, que encontrándose en esta situación estrellaron de manera deliberada sus aparatos contra objetivos enemigos" (Axell y Kase 2005: 94) ${ }^{24}$. Por lo que se refiere al término empleado en el japonés de la época, se popularizó en Japón en octubre de 1944, cuando los periódicos y las radios niponas comenzaron a emplear con profusión la palabra, la cual fue mencionada por primera vez en la prensa en agosto de 1944 (Axell y Kase 2005: 91-92, 94). Las documentaciones de «camicace» concuerdan con estas explicaciones históricas, puesto que en la primera muestra hispánica (de 1937), anterior a la Segunda Guerra Mundial, el término se emplea para nombrar una aeronave en la que viajaban aviadores japoneses, que regresaban a Toquio tras realizar un largo viaje ${ }^{25}$. Desde 1937 no se utilizan más ejemplos hasta 1944, esto es, hasta que no se han producido los ataques «camicace» en serie en el conflicto bélico entre Estados Unidos y Japón. De hecho, las documentaciones en la Hemeroteca se concentran en torno a estos años: 1944 y $1945^{26}$. Aclarado esto, hemos de situar el primer uso de «camicace» -con el valor semántico primitivo del que derivaron los demás ${ }^{27}$ - el 4 de noviembre de 1944 en Falange (Las Palmas de Gran Canaria): "Kamikaze". En otras lenguas europeas, su datación es próxima y siempre relacionada con la Segunda Guerra Mundial: así, en inglés,

24 En esta misma línea se mueve Hill (2006: 1), quien describe que: "Throughout the Pacific War, aircraft crashed into enemy ships. Such attacks increased from the battle for Guadalcanal in the latter half of 1942".

25 Dado que en el texto se dice: "que la última etapa, Indochina, Formosa, Tokio, fué bien terminada a pesar de las condiciones muy desfavorables de viento y tempestad", creemos que no se está haciendo referencia a ningún tipo de conflicto bélico, ni siquiera a la segunda guerra sino-japonesa, ya que esta se libró entre el 7 de julio de 1937 y el 9 de septiembre de 1945 (Junqueras, Madrid y Martínez 2013; Hane 2015; Walker 2017) y la noticia analizada se publicó el 21 de mayo de 1937.

26 Las razones históricas recién expuestas explican además que esta voz no fuera analizada por Dalgado, ya que el autor la publicó su glosario en 1919 y 1921, antes del suceso descrito.

27 Nos referimos a 'avión, o su piloto, cargado de explosivos, que en la Segunda Guerra Mundial se estrellaba voluntariamente contra su objetivo' (vid. Fernández Mata 2018b: 88). 
los primeros testimonios son de 1945 (MWCD y OED) ${ }^{28}$. El DHLP indica que la voz fue tomada cerca de 1945. Debido al protagonismo de Japón y Estados Unidos en la guerra, llama poderosamente la atención que los primeros registros de este japonesismo se documenten antes en español e italiano que en la propia lengua inglesa. En italiano, DELI, DOVLI y Zingarelli indican que el primer uso se ubica en $1944^{29}$. En cuanto a la lengua francesa, las fuentes no se ponen de acuerdo: PR fecha su primer caso en 1950, aunque el Trésor, el DHLF y Colby Knowlton (1959: 604) lo sitúan en 1953. ¿Cómo es posible que investigadores del francés no hayan descubierto documentaciones anteriores en periódicos que informaran sobre el conflicto bélico nipoamericano? Pese a que la cronología de las primeras documentaciones es anterior en español e italiano, la obviedad histórica y el patrón transcriptivo de la voz - para la que se ha empleado un sistema ortotipográfico extranjerizante ${ }^{30}$ - nos obligan a pensar que este japonesismo, al menos gráficamente, pasó a Occidente por mediación anglosajona.

\begin{tabular}{|c|c|c|}
\hline \multicolumn{3}{|c|}{ «CATANA»/ka'tana/ } \\
\hline 1. ${ }^{a}$ doc. textual & $\begin{array}{l}\text { catanas } \\
\text { catana } \\
\text { catana }^{31} \\
\text { katana }^{32}\end{array}$ & $\begin{array}{l}\text { 1588: prior Manrique, Macán (Gil 1991: } \\
\text { 28-29) } \\
\text { 1609: Sucesos de las islas Filipinas de } \\
\text { Antonio de Morga, México (DCECH y } \\
\text { Frago 1997: 109) } \\
\text { 05/09/1885: La Ilustración católica } \\
\text { (Madrid) } \\
\text { 01/09/1906: La Nación militar }\end{array}$ \\
\hline 1. a doc. lexicográfica & $\begin{array}{l}\text { catan }^{33} \\
\text { catana }\end{array}$ & $\begin{array}{l}\text { 1729: Diccionario de autoridades } \\
\text { (NTLLE) } \\
\text { 1853: Domínguez, suplemento (NTLLE) }\end{array}$ \\
\hline
\end{tabular}

28 Sin embargo, el OED aporta una documentación de 1896, en la que el término (Kamikazé) se emplea para referirse al viendo divino que salvó a los japoneses de la invasión mongola.

29 El 3 de diciembre en el Corriere della Sera (DELI). Por lo que la documentación española es anterior.

30 Un hispanohablante, de manera intuitiva, habría adaptado la voz como camicace.

31 Se trata de un texto en el que se recuerda lo que le sucedió al jesuita fray Luis de San Vítores en las Islas Marianas. Esta muestra aislada seguiría la estela de los casos compilados por el Diccionario histórico de la lengua española (1933-1936), ya que todos ellos, como indica el DCECH, son textos del siglo XVII referentes al Extremo Oriente.

32 El autor utiliza "el katana", en masculino (tal vez por influjo del uso lexicográfico, que otorgaba a catán género masculino) y con $k$ extranjerizante. ¿Por qué no siguió la tradición lexicográfica de adaptar la voz con c? ¿Acaso fue influido por el sistema anglosajón Hepburn?

33 En la definición de la voz se emplea la forma femenina: "Una espécie de alfange que usan los Indios, que en el Japón le llaman Catána” (NTLLE). 
Como ya concluimos en Fernández Mata (2015a), en el español de hoy existe el doblete catán-catana, cuya variante masculina fue producto de un error cometido en la redacción del Diccionario de autoridades ${ }^{34}$ y perpetuado por las siguientes obras lexicográficas que tomaban aquella como referente. Todavía se conserva la forma masculina en el DLE de 2014 (y actualizaciones), pese a que fuera de los textos lexicográficos - es decir, fuera de los propios diccionarios- no hemos hallado ni una muestra de catán (CORDE, CORDIAM, CREA, CORPES XXI y Hemeroteca ${ }^{35}$ ). Manejamos varias fechas para el primer registro escrito de la variante femenina, de la que sí hemos constatado ejemplos fuera de los diccionarios. En primer lugar, el CORDE ofrece el año de 1622 para el plural, catanas. En segundo lugar, el DCECH y Frago (1997) datan en 1609 la forma catana. Sin embargo, gracias a la obra de Gil (1991: 28-29), podemos adelantar su primera aparición escrita al año de 1588, cuando el prior Manrique, del monasterio de San Agustín de la ciudad de Macán, dirigió a Felipe II el 1 de marzo de $1588^{36}$ una misiva en la que escribe:

La gente es muy linpia y pulida en su trage, muy belicosa y valiente y armada de todas armas y buenos arcabuzes, lanças, catanas, que cortan a un hombre de un golpe, arcos, flechas, murriones y pecho y espalda (Gil 1991: 29).

Por tanto, aunque inusual ${ }^{37}$, es de esperar que este japonesismo fuera utilizado en castellano décadas anteriores a 1588, especialmente fuera de España, entre los primeros hispanohablantes en pisar tierra japonesa. Según Frago (1997: 112), este vocablo aparece recogido por primera vez en suelo español en un acta del cabildo sevillano, fechada el 27 de octubre de $1614^{38}$. Examinados todos los datos de que disponíamos, podemos sostener que la forma femenina de este doblete "erróneo" sufrió lo que Álvarez de Miranda (2004: 1039) denomina poligénesis temporal ${ }^{39}$, esto es, entró a lo largo de diferentes épocas

34 Se creyó que el sustantivo plural utilizado por la "autoridad" (Bartolomé Leonardo de Argensola, Conquista de las islas Malucas, 1609), "catanes", aun estando definido por el adjetivo femenino "diuersas", procedía de una forma masculina y singular, que reconstruyeron como catán. Para ampliar la información, vid. Fernández Mata (2015a).

35 Hemos actualizado los datos en este artículo, puesto que en 2015a desconocíamos la fuente de recursos que constituía la Hemeroteca.

36 No obstante, los hechos que relata son del año 1584.

37 Frago (1997: 110-111) afirma que: "este vocablo no debió pasar de un uso bastante minoritario y de constituir una verdadera rareza el objeto en cuestión”. Para esta apreciación se basa en el dicen de la descripción aportada por la obra lexicográfica de Terreros y Pando (1786, NTLLE): "dicen que es una especie de alfanje indiano".

38 Información que obtiene de Gil (1991: 396), quien relata la historia de la embajada de japoneses que llegó a España, en septiembre de 1614, bajo el mando del samuray Jasecura.

39 Álvarez de Miranda (2004: 1039) aconseja que: "el estudioso de la historia del léxico debe tener muy presente $[\ldots]$ la discontinuidad en la trayectoria de algunas acuñaciones y préstamos". 
de nuestro idioma: en los primeros contactos (finales del XVI e inicios del XVII) y tras la apertura de Japón al mundo (finales del XIX y principios del $\mathrm{XX})^{40}$. De las lenguas occidentales consultadas, atendiendo solo a una primera etapa de introducción, el portugués es la primera en recoger dicho japonesismo, en 1582 (catanà), según Dalgado (1919-1921) y DHLP. El inglés, el OED data sus primeras apariciones entre 1613 y 1615 (cattan/s). El Zingarelli sostiene que su primer testimonio aparece en 1636 (catana). Mientras que en las primeras adaptaciones del XVI y el XVII se emplea el grafema $c$, en las transcripciones del XIX se utiliza $k$ tanto en lengua española como en otras próximas: en inglés, desde 1874 en adelante, el OED solo registra katana. Aunque el Zingarelli sostenga que el primer caso de katana en italiano se documente en 1973, Colby Knowlton (1959: 612) halla un ejemplo de 1939. Única excepción parece la lengua portuguesa, que siempre usó $c$, de acuerdo con los testimonios de Dalgado (19191921), que van desde 1582 hasta 1885, y con las muestras del Corpus Lexicográfico do Português, que se mueven entre 1712 y 1755 . Parece, pues, que el proceso de poligénesis temporal es aplicable al resto de lenguas. Adviértase que, para la lengua española, nuestra propuesta cronológica no solo está motivada por los hechos históricos (primeros contactos, expulsión de misioneros, apertura Meyi, etc.), sino por las pruebas gráficas: en los contactos iniciales, los autores adaptan la voz de manera intuitiva, siguiendo los patrones ortotipográficos de nuestra lengua: catana; sin embargo, ya en 1906, con el sistema de transcripción extranjerizante Hepburn instaurado ${ }^{41}$, los autores sufren las influencias de este: katana. Por lo que respecta a los descriptores etimológicos, desde el diccionario de Alemany y Bolufer (1917) hasta la vigesimoprimera edición del DLE (1992), se le ha dado etimología de origen árabe. Desde Alemany y Bolufer (1917) hasta la decimoséptima edición del DLE (1947) se indicaba que el significado de su étimo era el de 'sable', mientras que desde la decimoctava edición del DLE (1956) hasta la vigesimoprimera (1992) se describía como 'cortante'. Por fin, en la vigesimosegunda edición del DLE (2001) se incluyó el verdadero origen etimológico bajo el descriptor: "(Del jap. katana, espada)” (NTLLE).

40 El propio Dalgado (1919-1921: XXXI) lo advierte en la introducción de su obra y, entre muchos ejemplos, incluye el de catana:

"Finalmente, convêm observar que nos séculos XVI e XVII eram mais conhecidos e estavam mais vulgarizados em Portugal do que nos nossos tempos muitíssimos termos orientáis, que depois caíram em desuso, tais como, conforme os nossos historiadores e dicionaristas antigos: [...] catana".

41 La difusión de este sistema, producto de la colaboración entre Hepburn y el Club de la Romanización - una sociedad formada en Japón por extranjeros y japoneses con el fin de promover la escritura en alfabeto latino en 1885-, tuvo mayor alcance tras publicarse la tercera edición de su célebre diccionario: A Japanese-English and English-Japanese Dictionary (1886) 


\begin{tabular}{|l|l|l|}
\hline \multicolumn{3}{|c|}{ «DAIMIO»/'daimio/ } \\
\hline \multirow{3}{*}{ 1. $^{\text {a doc. textual }}$} & $\begin{array}{l}\text { Daimio } \\
\text { daimyo }\end{array}$ & 18/03/1863: La Esperanza (Madrid) \\
& Daimyo & 09/08/1913: La Correspondencia de \\
& España \\
& daimyó & 15/10/1921: La Libertad (Madrid) \\
\hline \multirow{2}{*}{ 1. a doc. lexicográfica } & daimío & 1895: Zerolo (NTLLE) \\
& daimio & 1917: Alemany y Bolufer (NTLLE) \\
\hline
\end{tabular}

Sin lugar a dudas, el que una voz con una sustancia fonética tan similar a la de la lengua prestataria cuente con tantas variantes gráficas se debe, principalmente, a la intervención de una o varias lenguas. No obstante, de todas las adaptaciones, la más congruente con respecto a nuestro sistema ortotipográfico -que de hecho es la que propone nuestro método de transcripción, «daimio»- ha sido la preferida de los usuarios desde su primera documentación en 1863. Por otro lado, daimyo -con y sin mayúscula iniciales una variante que se mantiene con regularidad hasta 1925. Después de este año, existen casos repartidos (algún que otro con tilde en la vocal final, daimyó) desde 1958 hasta $2019^{42}$. La irregularidad que ha sufrido esta voz se puede comprobar también en la documentación lexicográfica, ya que Zerolo, el primero en inventariar la voz, usó un patrón acentual diferente al del étimo (daimío). Alemany y Bolufer, en 1917, corrigió este error para adecuarlo a la pronunciación preferida y etimológica (daimio). En la edición del DLE de 1956, la Academia incluyó este japonesismo por primera vez, aunque con un descriptor etimológico deficiente: "Voz japonesa". Así la mantuvo hasta una reciente actualización (2019) del DLE 2014, en la que se aporta el étimo y la traducción de este: "Del jap. daimio; literalmente 'gran nombre". Desde sus primeros registros, pues, observamos variación gráfica y acentual que se ha perpetuado hasta nuestros días (CORPES XXI, Hemeroteca), aunque las obras lexicográficas actuales prefieran la acentuación paroxítona, esto es, la grafía daimio (DEA, DLE 2001, GDUEA, DUE y DLE 2014). De las lenguas occidentales consultadas, la primera documentación tiene lugar en inglés ${ }^{43}$ : en 1727 (MWCD) o 1839 (OED). La siguiente en registrarlo fue el francés: 1822 (Colby Knowlton 1959: 510), 1854 (Dalgado 1919-1921) o 1863 (PR). De cerca le sigue el portugués, 1874 (Dalgado 1919-1921). Para el italiano contamos con dos fechas: 1888 (Zingarelli) y 1889 (DOVLI).

(Rodríguez-Izquierdo 1991: 124-125; Seeley 2000: 138-151; Vance 2008: 239-244; Gottlieb 2010: 75-78).

42 Prieto informa sobre esta variante (2007: 197).

43 En realidad, sería en lengua portuguesa, aunque esta responde a la primera etapa de contactos entre japoneses y lusos (1585: Daimeós, Dalgado 1919-1921). 
La historia de este vocablo podría ser un claro representante de la idea que desarrollaremos en el apartado de conclusiones: existe una lucha ${ }^{44}$ entre las adaptaciones fieles a nuestro sistema ortotipográfico y aquellas extranjerizantes. En este en concreto, pese a que rápidamente las obras lexicográficas de la lengua española acomodaron el término a nuestra ortografía, existen adaptaciones con aire exótico. Desde nuestro punto de vista, estas se deben a la acción de: (1) el sistema de romanización Hepburn (este método transcribe la cadena sonora del japonés /mjo/ como myo) ${ }^{45} ;(2)$ la intermediación de una lengua extranjera, inglés ${ }^{46}$ o francés, pues ambas cuentan con una variante con myo (daimyo MWCD, daimyo PR, DFL, Trésor).

\begin{tabular}{|c|c|c|}
\hline \multicolumn{3}{|c|}{ «JARAQUIRI» / xara'kiri/ } \\
\hline 1. ${ }^{a}$ doc. textual & $\begin{array}{l}\text { harra-kiri } \\
\text { Harakiri } \\
\text { Kara-Kiri } \\
\text { Hara-Kiri }\end{array}$ & $\begin{array}{l}\text { 14/09/1866: La Esperanza (Madrid) } \\
\text { 18/05/1868: La Esperanza (Madrid) } \\
\text { 07/08/1868: La Epoca (Madrid) } \\
\text { 20/03/1886: La Epoca (Madrid) }\end{array}$ \\
\hline 1. a doc. lexicográfica & Harakiri & 1918: Rodríguez Navas (NTLLE) \\
\hline \multicolumn{3}{|c|}{$\begin{array}{l}\text { Documentamos en los siglos XVI y XVII, durante los primeros contactos } \\
\text { de lusos e hispanos con el pueblo nipón, testimonios en los que se describe } \\
\text { esta práctica, pero sin recurrir a la etiqueta: "E por ser costume universal } \\
\text { de Japão dos senhores nobres, principaes e capitães de fortalezas cortarem } \\
\text { elles por sy mesmos os peitos e entranhas" (texto de 1549-1593; Fróis 1981: } \\
\text { 381); "Y si os tardares, será menester cortaros el hombligo" (texto de 1592; } \\
\text { Gil 1991: 42); "cortam a barriga em Cruz com a ponta da adaga" (texto } \\
\text { de 1607; Dalgado 1919-1921: 455). El término tardaría casi tres siglos en } \\
\text { aterrizar en suelo hispánico, pues la primera documentación textual se sitúa } \\
\text { en 1866, justo antes de la apertura Meyi (Junqueras, Madrid y Martínez } \\
\text { 2013; Hane 2015; Walker 2017). El primer diccionario en incluir la voz fue } \\
\text { el de Rodríguez Navas en 1918. La Real Academia no la catalogaría hasta la } \\
\text { edición de 1970, en la que aparece por vez primera un descriptor etimológico: } \\
\text { "Del japonés "cortar el vientre"". Este se abrevió en la edición de 1984: "Voz } \\
\text { japonesa". Desapareció en el manual de } 1989 \text { y regresó al DLE de } 1992 .\end{array}$} \\
\hline
\end{tabular}

44 También detectamos variación gráfica en otras lenguas: en inglés coexisten daimyo y daimio (MWCD y OED); en francés, daimyo y daïmio (DFL y PR); en portugués, daimiô, daimio, dáimio, daimió (DHLP y DPLP). Solo el italiano presenta uniformidad: daimio (DOVLI y Zingarelli).

45 Esto es así en la tercera edición (1886), pues en la primera (1867) Hepburn transcribe miyo.

46 Probablemente fuera la lengua inglesa, puesto que sus registros son anteriores a los españoles y los franceses. 
Así se mantuvo en la vigesimosegunda y vigesimotercera edición, en las que solo se señala su origen japonés, sin indicar el étimo. En una reciente actualización se ha agregado la información pertinente ${ }^{47}$ : "Del jap. coloq. harakiri, de hara 'vientre' y kiri 'corte",. Por lo que respecta a otras lenguas occidentales, su datación es similar, en torno a la segunda mitad del siglo XIX: en inglés, las primeras muestras son de 1840 (MWCD) y 1856 (OED); en francés, primera lengua románica en tomarla, se ubica en 1854 (Dalgado 1919-1921) o en 1863 (PR) ${ }^{48}$; de cerca le sigue el portugués, ya que su primer registro es de 1874 (Dalgado 1919-1921 y DHLP); en último lugar, para el italiano, su primera documentación textual se sitúa en 1889 (DELI, DOVLI y Zingarelli). Por los errores antietimológicos de las primeras adaptaciones (harra y kara) y por el uso del guion y de la $k$ exótica, creemos que una lengua extranjera intermedió entre el japonés y el español. Después de analizar los datos de que disponíamos, podemos concluir que la lengua francesa y su adaptación propia influyeron de algún modo en la transcripción gráfica de este japonesismo en lengua española: (1) sus testimonios son cronológicamente anteriores; (2) desde sus primeros registros se suele emplear también el guion en francés ${ }^{49}$; (3) en 1864 Colby Knowlton (1959: 557) halla un caso de harra-kiri, dos años anterior a nuestra primera documentación, que coincide con la gala; (4) en cinco de un total de siete muestras de las documentaciones recogidas por el OED, se prefiere la forma errónea hari-kari para el inglés, por lo que esta lengua tuvo menos posibilidades de influir; (5) desde un punto de vista sociocultural, el francés era la lengua poderosa en el siglo XIX (Guerrero 1995; Gómez Capuz 2004; Lapesa 2005; Álvarez de Miranda 2004; Ortega 2011); y a este respecto, no debemos olvidar que en 1873, una obra enciclopédica de referencia, el Grand Dictionnaire universel du XIX ${ }^{e}$ siècle, dedicaba casi una columna a explicar este ritual ${ }^{50}$.

47 Como concluimos en Fernández Mata (2016a), el tratamiento etimológico de los japonesismos en las obras de las Academias era deficiente. No obstante, se aprecia en las actualizaciones del DLE (2014) esfuerzos para mejorar este aspecto.

48 Según el Trésor, hara-kiri aparece por primera vez descrita en 1873 en el GDU XIX. Sin embargo, en línea leemos que el tomo 9 en el que se publicó la voz es de 1872 (Cf. https:// gallica.bnf.fr/ark:/12148/bpt6k2053614/f903.item.r=hara-kiri).

49 Dalgado (1919-1921) localiza la forma hara-kiri en el primer registro portugués de 1874. ¿Se basarían los redactores del DPLP en Dalgado (1919-1921) para determinar que la voz pasó a través del francés?

50 Cf. en el tomo 9 descrito en nota 48 . 


\begin{tabular}{|l|l|l|}
\hline \multicolumn{3}{|c|}{ «MICADO»/mi'kado/ } \\
\hline \multirow{2}{*}{ 1. $^{\text {a doc. } \text { textual }}$} & Mikado & 08/11/1857: La América (Madrid) \\
& Micado & 24/11/1857: La América (Madrid) \\
\hline 1. $^{\text {a }}$ doc. lexicográfica & Mikado & 1884: DLE (NTLLE) \\
\hline
\end{tabular}

En cuanto a su acepción originaria ${ }^{51}$-'(título del) emperador del Japón'-, de acuerdo con los datos de la Hemeroteca, Luis de Estrada, periodista de La América, introdujo esta voz en unos artículos en los que hacía una revisión del comercio de Japón con otras naciones. Sorprende que el autor, con menos de un mes de diferencia, emplee dos adaptaciones diferentes, ambas con paráfrasis explicativas, la primera más extensa que la segunda: "el Mikado ó Dairi (pontífice ó emperador espiritual), cuya autoridad es tan venerada como la de Sjogun ó emperador temporal" (8 de noviembre); "al Micado ó emperador espiritual del Japon" (24 de noviembre). La equivalencia que De Estrada propone entre «micado»y «dairi» se explica por razones históricas, las cuales quedan resumidas en la definición de «micado» que realiza Dalgado (1919-1921): “Título do imperador do Japão. Não figura o vocábulo nos escritos dos nossos missionários antigos, que designam o soberano espiritual por dairi [...], e o temporal por cubó [...]. Com a abolição do xogunado [...] no século pasado, ambos os poderes estão reunidos em uma só entidade". Esta misma idea se infiere en la descripción etimológica e histórica del Trésor, pues en la primera documentación francesa -situada antes del fin del «siogunado» (1803) - «micado» se emplea con el valor de 'chef de la religion au Japon', mientras que el significado de 'empereur du Japon' se registra en 1872. Esta situación también se atestigua en la lengua española: en los textos recogidos por Gil (1991) -relativos a la época de primeros contactos ${ }^{52}$, no hallamos ni un solo caso de «micado», pero sí algunos ejemplos de daire / daide / dayre(s) / Cubozama: "como las da el daire y rey del Japón” (p. 162); "En esta ciudad reside el dayre, que es el rey del Japón” (p. 180); "Antiguamente los que llaman dayres y sus deudos gobernavan, y no eran estimados los soldados como ahora en el Japón. [...] Llaman a estos reyes el dayre o jesico. [...] Los emperadores del Japón llaman Tencadoni, y la dignidad es de Segun ${ }^{53}$ Cubozama, que es lo mismo, y sama quiere decir 'señor' y cubo o segun dice lo propio que 'capitán general' o 'dictador', como decían los romanos.

51 Para conocer acerca de los valores semánticos del término en español actual, vid. Prieto (2007) y Fernández Mata (2018b).

52 Colby Knowlton (1959: 513) sitúa una primera documentación en Lope de Vega (1618) para «dairi» y ninguna en lengua española para «cubó(sama)».

53 ¿Nos encontraríamos ante la primera aparición de «siogun» en lengua española? ¿Acaso el autor, por analogía con la preposición castellana, transcribió el material fonético del japonés 
Esta dignidad de emperador la da el dayre, y él va a recibirla antes de entrar en su gobierno" (p. 201); "y esto hazen cuando elijen dayre, qu'es el que da las dignidades, que entre ellos es como Sumo Pontífize entre nosotros" (p. 331); “donde está el dayde, de quien toman la vendiçión los reyes y señores cuando les dan las dignidades, y es muy respetado del enperador y los demás. [...] Son los reyes legítimos del imperio" (p. 371) -todos pertenecen a textos de 1609, a excepción de los dos últimos, de 1611-. Los testimonios de Dalgado (1919-1921) respaldan esta teoría, ya que documenta muestras de «dairi» (en portugués: desde 1564 hasta 1635; en francés ${ }^{54}$ : desde 1640 hasta 1854) y de «cubo» (en portugués: desde 1549 hasta 1874; en italiano: uno en 1588; en francés: desde 1640 hasta 1854). Por algún motivo que desconocemos, a lo largo del siglo XIX la voz «micado» acabó por sustituir en la literatura occidental a los términos que se habían estado usando desde los primeros contactos (siglos XVI y $\mathrm{XVII})^{55}$. Esto explica que Luis de Estrada equiparase ambos términos, pese a que solo «dairi» fuera inventariado en obras lexicográficas. Según el NTLLE, «dairi» se mantuvo desde 1786 (en la obra de Terreros y Pando) hasta 1918 (Rodríguez Navas) y nunca fue incluida en un diccionario de la RAE. El primer diccionario en el que se relacionan ambos términos es el de Zerolo (1895): "El dairo, conocido también más comunmente con el nombre de mikado, asume el poder espiritual y el temporal". El hecho de que ninguna de las obras cercanas ${ }^{56}$ a su primera documentación textual recogiera algún tipo de referencia a «micado» nos inclina a pensar que la voz tomó mayor fuerza en lengua española durante las últimas décadas

como segun? Pese a que el autor adapta con fidelidad los japonesismos, creemos que aquí pudo cometer un desliz, puesto que el contexto obliga a que sea «siogun».

54 Colby Knowlton (1959: 512) localiza usos de «dairi» en Voltaire (1740 y 1772) y Víctor Hugo (1852).

55 ¿Se explicaría por los cambios históricos que sufrió Japón en el siglo XIX? No lo creemos. Asakawa, en 1903, aclara en una nota a pie de página lo siguiente:

"We purposely avoid, in spite of its wide usage in foreign literature, the misleading term Mikado. If it be not for the natural curiosity of the races, which always seeks something novel and loves to call foreign things by foreign names, it is hard to understand why this obsolete and ambiguous word should so sedulously be retained. It originally meant not only the Sovereign, but also his house, the court, and even the State, and its use in historical writings causes many difficulties which it is unnecessary to discuss here in detail. The native Japanese employ the term neither in speech nor in writing. It might as well be dismissed with great advantage from sober literature as it has been for the official documents" [Negrita nuestra] (1903: 25).

56 Tal es el caso de los diccionarios de Domínguez (suplemento, 1853), Gaspar y Roig (1853) y Domínguez (suplemento, 1869). Parece especialmente esclarecedor que en la extensa explicación histórica de Gaspar y Roig no se dedique ni una línea a tratar sobre la equivalencia de dichos vocablos: "título del soberano del Japon a quien está confiado el poder espiritual, y cuya familia está mirada como descendiente de las antiguas divinidades que reinaron en 
del siglo XIX ${ }^{57}$. La Hemeroteca reúne en torno a 150 ejemplos de «micado» desde su primera documentación (1857) hasta 1900, en contraposición a 26 casos de «dairi» para ese mismo periodo. Muy probablemente «dairi» se mantuviera como voz en desuso en las obras del siglo XX: 1901 (Toro y Gómez), 1917 (Alemany y Bolufer) y 1918 (Rodríguez Navas). Así, por ejemplo, leemos en Alemany y Bolufer: "Antiguamente el dairi era el único soberano del Japón; hoy su soberanía es más de nombre que de hecho. Llámase también mikado". En definitiva, en la segunda mitad del siglo XIX la voz «micado» acabó por imponerse a otros términos (dairi, daire, cubo...), títulos que se perdieron con las transformación histórica acaecida en el país del sol naciente. En cuanto a la datación de «micado» en otras lenguas occidentales, la implantación es anterior en francés (1803: Trésor y DHLF; 1827: PR), italiano (1834: DOVLI y Zingarelli) e inglés ${ }^{58}$ (1845: OED); y análoga: en portugués (1854: Dalgado 1919-1921 y DHLP). Por la cronología de su primera documentación y por la hegemonía de la lengua en la época, creemos que la lengua francesa, de algún modo, hubo de influir en la transcripción con $k$ extranjerizante. Además, el GDU XIX describe el lema Mikado o Mikkado en el tomo 11. Desde la edición de 1884, la Academia ha registrado la forma "mikado", y su adaptación, "micado", desde 1899. Introdujo descriptor etimológico en el DLE de 1936: "Del japonés mi, sublime, y cado, puerta", y así lo ha mantenido hasta la actualidad.

el país. En su oríjen los Dairis reunían los dos poderes espiritual y temporal, siendo a la vez generales y pontífices, lejisladores y patriarcas; pero a fines del siglo XII los jefes de la milicia comenzaron a desposeerlos de la autoridad real separándoles primero de los asuntos políticos y privándoles después de toda influencia ejecutiva. El Dairi reside en Meaco, goza de inmensas riquezas y tiene doce mujeres lejítimas. Es mirado como el oráculo de la relijion, se le venera como a Dios y se ejecuta cuando manda no oponiéndose a la autoridad del Cubo, que es el jefe del poder temporal. Sin embargo, no puede salir de la ciudad, y se encuentra realmente sometido a la vijilancia recciosa del emperador verdadero". Tampoco se dice nada al respecto en las descripciones de Domínguez (1853 y 1869).

57 En otros sistemas lingüísticos, la sustitución de un término por otro se había completado en la primera mitad del XIX. Así, leemos en la información etimológica del OED, relativa a The Encyclopaedia Metropolitana (1845), que: "Their Spiritual ruler is the Mikaddo, i.e. Sublime Porte, a term commonly used to express the Daïri himself as well as his Court".

58 Descartamos un primer testimonio en inglés, pues se trata de un uso circunstancial relativo a una traducción de 1727 de Kaempfer (MWCD, OED). En ella el autor ofrece una etimología de la voz y equipara el vocablo a otros sinónimos, pero, por encima de todos, se prefiere «dairi»:

"They are call'd Mikaddo (which is a diminutive of Mikotto) as also Dai, and Oo, and Kwo and Tai, all which signify an Emperor, a Prince and great Lord. They are likewise call'd Tensin, that is, Sons of Heaven, and many more Titles of the like Nature have been given them. In common conversation they are frequently call'd Dairi, which name properly denotes their whole Court, on which account also he is 


\begin{tabular}{|c|c|c|}
\hline \multicolumn{3}{|c|}{ «SAMURAY»/samu' rai/ } \\
\hline 1. ${ }^{\text {a }}$ doc. textual & $\begin{array}{l}\text { samurais } \\
\text { samuray }\end{array}$ & $\begin{array}{l}\text { 02/12/1874: La Época (Madrid) } \\
\text { 01/11/1897: Ilustración artística }\end{array}$ \\
\hline 1. ${ }^{\mathrm{a}}$ doc. lexicográfica & samuray & 1918: Rodríguez Navas (NTLLE) \\
\hline $\begin{array}{l}\text { Pese a la estrecha rela } \\
\text { sus documentaciones t } \\
\text { a las de aquella, muy } \\
\text { japonés, en } 1868 \text { (Trés } \\
\text { Hane 2015; Walker } 2 \\
\text { del «samuray», puso c } \\
\text { informativas de la épo } \\
\text { incluida en una obra } \\
\text { información etimológi } \\
\text { vez en la edición de 1s } \\
\text { (samuray) únicamente } \\
\text { étimo en } 2001 \text { : Del jap } \\
\text { hasta la actualidad (2 } \\
\text { aportados por el DU } \\
\text { «samuray» surgió en to } \\
\text { en las lenguas occider } \\
\text { justo con la apertura a } \\
\text { internacional (Junquer } \\
\text { en lengua francesa, el } \\
\text { en } 1852^{61} \text {. Por lo que } \\
\text { la misma fuente, la Hi } \\
\text { Portugueses de Fernãc } \\
\text { año: } 1552 \text { çamurai (D } \\
\text { esta primera alusión p } \\
\text { ejemplos ya en la segun } \\
\text { también en el mismo añ } \\
\text { como DOVLI y Zingal } \\
\text { enciclopedia Hoepli, } \\
\text { que la voz se usaba "a } \\
\text { "ricorrente nelle molt }\end{array}$ & $\begin{array}{l}\text { ión semánt } \\
\text { xtuales y le } \\
\text { probablem } \\
\text { r; DHLF; } \\
\text { 17), cuyo } \\
\text { e moda el } \\
\text { a. Poco tie } \\
\text { exicográfic } \\
\text { a, NTLLE } \\
56 \text { (samura } \\
\text { se indicó su } \\
\text { samurai. I } \\
\text { 20), pero s } \\
\text { AE, el DI } \\
\text { rno al siglo } \\
\text { tales se cor } \\
\text { mundo de } \\
\text { s, Madridy } \\
\text { R, el Tréso } \\
\text { especta al } \\
\text { tória do D } \\
\text { Lopes de } \\
\text { lgado, } 191 \\
\text { rece circun } \\
\text { da mitad de } \\
\text { y en plural } \\
\text { elli docume } \\
\text { irigida por } \\
\text { tempo dell } \\
\text { recenti pu }\end{array}$ & $\begin{array}{l}\text { ico-conceptual de esta voz con «busido», } \\
\text { xicográficas preceden con gran diferencia } \\
\text { ente porque la abolición del feudalismo } \\
\text { ED; Junqueras, Madrid y Martínez } 2013 \text {; } \\
\text { náximo exponente tangible era la figura } \\
\text { érmino, como así leemos en las crónicas } \\
\text { mpo tuvo que pasar para que la voz fuera } \\
\text { a, la de Rodríguez Navas en } 1918 \text { (sin } \\
\text { La Academia la incorporó por primera } \\
\text { i), desde ese año hasta la edición de } 1992 \\
\text { procedencia japonesa. La RAE añadió el } \\
\text { pescriptor etimológico que ha conservado } \\
\text { in traducción. De acuerdo con los datos } \\
\text { JE, el DFL y el DOVLI, el estamento } \\
\text { XII }{ }^{60} \text {. Sin embargo, sus primeras muestras } \\
\text { icentran en las últimas décadas del XIX, } \\
\text { Japón y su incesante participación bélico- } \\
\text { Martínez } 2013 \text {; Hane 2015; Walker } 2017 \text { ): } \\
r \text { y el DHLF fechan su primera aparición } \\
\text { portugués, aunque ambas obras aluden a } \\
\text { escobrimento e Conquista da Índia pelos } \\
\text { Castanheda, no se ponen de acuerdo en el } \\
\text {-1921) y } 1559 \text { (DHLP). Sea como fuere, } \\
\text { stancial, pues Dalgado (1919-1921) halla } \\
\text { siglo XIX; el primero en 1874 (samouraís, } \\
\text { como en español). En italiano, tanto DELI } \\
\text { ntan su primer caso en } 1895 \text {, en la Piccola } \\
\text { Garollo (1892-1895). En DELI se detalla } \\
\text { a guerra ruso-giapponese" y que era muy } \\
\text { oblicazioni che trattano del Giappone"62. }\end{array}$ \\
\hline
\end{tabular}

\footnotetext{
sometimes call'd Kintsiusama, that is, the Head, or Lord of the Ecclesiastical Court" [Negrita nuestra] Kaempfer (1727: 259-260).

59 Como curiosidad, se trata de un reportaje firmado por Emilia Pardo Bazán.

60 El PR adelanta la aparición de los samuráis alrededor del siglo X.

61 De acuerdo con el Trésor, la siguiente documentación se registra en 1876.

62 Información que obtienen del Dizionario moderno de Panzini (la edición de 1908).
} 
En cuanto a la lengua inglesa, pese a que su primer registro tenga lugar en una traducción de Kaempfer de 1727 (MWCD y OED), lo cierto es que las documentaciones que recoge el OED se aglomeran en torno a las últimas décadas del XIX: 1841, 1874, 1885, 1896, 1898, 1904. En español, en el periodo de propagación de la unidad, la adaptación gráfica de esta no violaba los preceptos ortotipográficos ${ }^{63}$ : samurais (1874). Como en otras voces, creemos que la lengua francesa pudo actuar como intermediaria, principalmente por escritos enciclopédicos y de prensa: (1) su primera muestra es anterior a la española (1852 vs. 1874); (2) recordamos, otra vez, su hegemonía como lengua universal; (3) según Colby Knowlton (1959: 686), existe un temprano uso en la literatura gala, un soneto titulado "Le Samouraï" (c. 1884) y que en español se tradujo como "El Samurai" (en 1904); (4) pese a que durante los primeros contactos de lusos con nipones, como demuestra Dalgado (1919-1921), el término se adaptaba con grafía fiel a la tradición escrita del portugués, en la reintroducción de la segunda mitad del siglo XIX, 1874, se usa la transcripción samouraís, la cual, sin duda, hubo de venir de una forma francesa: samouraï. Desde 1876, advertimos algunos usos de S/samourai(s), con la combinación francesa ou, en la Hemeroteca para la lengua española.

\begin{tabular}{|l|c|l|}
\hline \multicolumn{3}{|c|}{ «SIOGUN»/'sioguN/ } \\
\hline 1. $^{\text {a }}$ doc. textual & Sjogun $^{64}$ & $08 / 10 / 1857:$ La América (Madrid) \\
\hline 1. $^{\text {a }}$ doc. lexicográfica & sogun / xogun & 1931: Pagés (NTLLE) \\
\hline $\begin{array}{l}\text { La primera vez que se introdujo en un diccionario de la lengua española fue } \\
\text { en 1931, en la obra de Pagés. Casi } 40 \text { años transcurrieron hasta que la RAE }\end{array}$ \\
$\begin{array}{l}\text { la incluyó en el suplemento de 1970, bajo la adaptación oxítona sogún. En } \\
\text { aquella ocasión la voz aparecía acompañada por un descriptor etimológico } \\
\text { incompleto (Del japonés šōgun), el cual ha sido conservado en ediciones } \\
\text { posteriores hasta la actualidad }\end{array}$. Observamos anarquía gráfica en las primeras \\
documentaciones textuales del término: Sjogun (desde 1843 hasta 1858),
\end{tabular}

63 Estaban vigentes las reglas de la novena edición de la ortografía (1820), en la que podemos leer: "Las voces acabadas en alguna de las letras consonantes se acentuarán en todas las sílabas en que cargare la pronunciacion, menos en la última, porque esta es comunmente larga en las voces de esta especie" (RAE 1820: 88).

64 De nuevo, el primer usuario fue Luis de Estrada. De acuerdo con la Hemeroteca, esta adaptación no perduró, pues detectamos algunos ejemplos hasta el 12 de febrero de 1858 ( $E l$ Isleño, Palma de Mallorca). En algunos de estos, incluso, hallamos una extraña transcripción: Seogun (La América, Madrid, 24 de octubre de 1857) -solución que también se documenta previamente en francés: seogoun (1836, DHLF)-.

${ }_{65}$ En una reciente actualización del DLE 2014, se ha modificado el étimo: de šōgun a shōgun. 
Ziogun (desde 1861 hasta 1886), Xogun (desde 1867 hasta 1923), Shogun (desde 1874 hasta 2019), Gio-gun ${ }^{66}$ (1883), Shogon(s) (1904), Sogun (desde 1906 hasta $2017^{67}$ ). El problema ${ }^{68}$ de análisis que presenta esta palabra radica en la transcripción del sonido palatal japonés y en su patrón acentual. Por lo que respecta al primero, la lengua española: (1) mantiene la palatalidad etimológica $(/ \mathrm{So} / \rightarrow$ sjo, zio, gio, sho, $x o$ ) o (2) la elimina $(/ \mathrm{so} / \rightarrow s o)$. En cuanto a la acentuación, como ya informamos en Fernández Mata (2018b), en los corpus (CORDE, CREA y CORPES XXI) se percibe un mayor número de casos con pronunciación paroxítona ${ }^{69}$, similar a la del étimo. En esta ocasión, hemos de añadir, además, las documentaciones de la Hemeroteca y de otras lenguas próximas (MWCD, OED, DHLP, DPLP, Zingarelli ${ }^{70}$ ), que desde sus inicios prefieren este patrón. Desconocemos por qué gran parte de las obras lexicográficas hispánicas describen una acentuación oxítona, puesto que para nada coincide con el uso mayoritario, real y etimológico de la voz (DEA, DLE 2001, DClave y DLE 2014). ¿Pudo deberse a la similitud con el significante según y el conjunto de voces que terminan en sílaba tónica/-un/? ¿Acaso el problema reside en el patrón acentual de la lengua prestataria? Millán (2019: 21), al respecto de la acentuación de japonesismos, sostiene que "la pronunciación tonal del japonés presenta una variación sincrónica y diacrónica importante", lo cual podría llevar a los autores a percibir "ciertas entonaciones diferentes a las del japonés estándar actual". Asimismo, estamos de acuerdo con Millán (2019: 21), quien cree que "el sistema tonal del japonés hace que a oídos hispanohablantes parezca que una misma palabra pueda estar acentuada en más de una sílaba". Sea como fuere, nuestro sistema de transcripción utiliza la fórmula más acorde al étimo y a la pronunciación hispánica: «siogun». La figura del «siogun» como gobernante de facto de todo Japón tuvo vigencia desde finales del siglo XII hasta la segunda mitad del siglo XIX (Gil 1991; OED; DHLP; NDVUA; Trésor; Prieto 2007; Junqueras, Madrid y Martínez 2013; Hane 2015; Walker 2017; DFL); de este modo, cabría esperar que la voz entrara durante ese periodo en la lengua española y otras occidentales. No obstante, su primera documentación hispánica se sitúa

66 En esta adaptación del Archivo diplomático-político de España (21 de septiembre de 1883) claramente no se ha sabido interpretar el punto de articulación del étimo. Hemos descubierto un ejemplo similar en lengua francesa, pues el DHLF documenta djogoun en 1830.

${ }_{67}$ En las últimas adaptaciones, las más recientes, con cambio acentual: sogún, pues siguen claramente los preceptos de la RAE.

68 La lengua española no ha sido la única en presentar esta confusión, pues en una documentación del OED, fechada en 1879, leemos: "The difficulty which modern writers have found in deciding upon the correct mode of spelling the single word Shôgun".

69 Como la que describe el GDUEA.

70 Aunque el DOVLI indica la acentuación contraria, esto es, oxítona. Otra prueba más de que esta voz presenta una gran variedad en las lenguas occidentales. 
en $1857^{71}$, mientras que la lexicográfica se fecha en $1931^{72}$. En otras lenguas extranjeras sus primeros testimonios se ubican dos siglos antes: en portugués, Dalgado (1919: 434) recoge la fórmula Xogum en 1607 y Xogúm en 1608. En inglés, el OED sitúa Shongo en 1615. Aunque DOVLI y Zingarelli sostengan que los primeros registros en italiano se ubican en 1960, Colby Knowlton (1959: 705) documenta adaptaciones italianas del siglo XVII: en 1644 (Sciogun) y c. 1661 (Xongun). Por lo que respecta a la lengua francesa, sus adaptaciones son irregulares y todas pertenecen al siglo XIX: 1830 (djogoun), 1836 (seogoun), 1875 (shogoun), 1881 (shogun) (Trésor y DHLF) ${ }^{73}$. Si bien, Colby Knowlton (1959: 706) encuentra un ejemplo de Xogun-Sama en 1715 y otro de seogun en 1772. A lo largo del XIX, también registra gran variedad de transcripciones: Djogoun (1822), Seogun (1832), siogoun (1857-58), Sio-goun (1861), chiogouns (1864), Shogoun (1879), shiogoun (1895) (Colby Knowlton 1959: 706). Tras la revisión de los datos, todo apunta a que este término contó con varias etapas de introducción en Occidente: el primer periodo se fecha a principios del siglo XVII y fue impulsado, al menos en el mundo romance, por los contactos lusos. Así se explican las adaptaciones italiana -Xongun (c. 1661) - y francesa -XogunSama (1715)-, que utilizan el grafema $x$ para marcar la palatalidad japonesa como hicieron los misioneros portugueses en 1607 (Xogum) y 1608 $(X o g u ́ m){ }^{74}$. El siguiente momento de introducción se sitúa a lo largo del siglo XIX, etapa en la que cristalizan infinidad de transcripciones, aunque finalmente se decide por el dígrafo $s h$ para marcar la consonante prepalatal, fricativa, japonesa. El caso más llamativo lo representan las transcripciones portuguesas, que abandonaron la tradición secular de emplear el grafema $x$ para esta voz. Dalgado (1919-1921) localiza muestras de sh desde 1874

71 Corregimos la información de Fernández Mata (2018b).

72 Pagés emplea este vocablo como sinónimo de taikún, correspondencia que aparece de nuevo en el DUE y que se tratará en profundidad en el análisis de «taicun».

73 La forma djogoun (1830) solo es documentada por el DHLF, mientras que shogun (1881) únicamente aparece en el Trésor.

74 Gracias a Dalgado (1919-1921), sabemos que desde los primeros contactos los portugueses utilizaban la $x$ para marcar el sonido palatal. Así, ofrece ejemplos desde 1607 hasta 1749. No creemos que el significante español Xogun (documentado desde 1867 hasta 1923) responda a parámetros portugueses, puesto que este grafema contaba con un amplio recorrido en el mundo hispánico: se empleaba en el español medieval para representar el fonema sibilante, prepalatal, sordo, $/ \mathrm{J} / \mathrm{y}$, por tradición, se mantuvo hasta la reforma ortográfica de 1815 (Lapesa 2005: 402-405; Salvador y Lodares 2008: 311-312; RAE y ASALE 2010: 108-109). Por tanto, es muy probable que la grafía Xogun respondiera más al peso de la tradición que a la influencia lusa. Además, si los castellanos transcribieron con $x$ las voces árabes (xurel>jurel) y amerindias (Xochimilco) en las que creían reconocer un sonido sibilante similar (Salvador y Lodares 2008: 313-314), ¿por qué no pensar que hicieron lo mismo con los préstamos de la lengua japonesa? 
hasta $1919^{75}$. Este cambio ha ocurrido en otras lenguas romances: francés (desde 1875: Trésor y DHLF), italiano (1939: Colby Knowlton 1959: 707) y español (véanse los casos de la Hemeroteca). Por lo que concierne a las adaptaciones hispánicas, salvo sjo o zio ${ }^{76}$ y $x o$-que acabamos de explicar-, creemos que las transcripciones que emplean la grafía sho podrían proceder tanto de la lengua francesa como de la inglesa ${ }^{77}$. Existen pruebas para pensar que la voz nos llegó a través del francés: (1) la lengua francesa era la lengua de transmisión internacional; (2) algunas transcripciones galas son anteriores a las hispánicas; (3) en La Dinastía (Barcelona: 19/02/1904) se traduce un texto aparecido en una publicación francesa en la que se utiliza el término Shogon $^{78}$. Sin embargo, son más numerosas las evidencias para sostener que la lengua inglesa, de alguna manera, intervino en el proceso de adopción: (1) las adaptaciones con dígrafo $s h$ son mucho más antiguas en inglés (1615: OED) que en francés (1875: Trésor y DHLF) y español (1904: Hemeroteca); (2) el sistema anglosajón Hepburn hubo de impulsar que los japonesismos que tuvieran dicho sonido fueran romanizados mediante $s h$; (3) por último, dos testimonios son clave para despejar esta incógnita: en primer lugar, las esclarecedoras palabras que el diplomático español Francisco de Reynoso emplea al inicio de su libro, En la Corte del Mikado (1904: XI):

Para facilitar la lectura de los nombres japoneses, de personas, cosas y lugares, contenidos en este libro, se ha tratado de armonizar, en lo posible, la pronunciación japonesa, con la ortografía castellana, tratando al mismo tiempo, de no alterar la estructura de las palabras, tal y como las escriben la mayoría de los autores occidentales que han publicado obras sobre el Japón en los últimos años, á fin de evitar la confusión que resultaría, de construirlas de modo diferente del usual y admitido, tanto en Europa como en América.

75 No obstante, él transcribe xógum. En la actualidad, los diccionarios portugueses DHLP y DPLP también emplean este significante.

76 Si en nuestro método de transcripción (Fernández Mata 2018c) marcamos la palatalidad con la transcripción sio, puede que los usuarios de aquel momento también pretendieran lo mismo mediante sjo o zio. Este método no fue extraño en Occidente, pues el propio Kaempfer, en su Amoenitates Exoticae (1712), emplea sjo y kjo para indicar la palatalización de la consonante anterior. De hecho, los sistemas de romanización creados a finales del XIX usaban un resultado similar, en el que $j$ era cambiado por $y$ : syo en lugar de sjo (Hepburn, 1886; Seeley, 2000: 142-178; Vance, 2008: 241-244).

77 Por lo que respecta a la lengua francesa, en la actualidad se transcribe como shogun o shogoun (DFL, DHLF y Trésor). En cuanto al inglés, la variedad es mayor: shogun (preferida), aunque algunos casos obsoletos de shongo, seogun, djogoun, s(h)iogoon, sjogun, ziogoon (MWCD y OED).

78 Leemos:

Bajo este mismo epigrafe y firmado por «Un Diplomático» publicó Le Journal y leemos traducido en La Correspondencia de España el siguiente interesante y curioso 
Así pues, Shogun, por ejemplo, está escrito con $s h$, sonido fonético inglés, que responde exactamente al japonés y no con $X$, que además de alterar por completo la fisonomía de la palabra, hasta el punto de hacerla imposible de conocer, no reproduce el sonido japonés.

En segundo lugar, Dalgado (1919-1921: XIX) se lamenta de las modificaciones visuales que sufrían en su época las voces asiáticas que ya contaban con patrones gráficos totalmente adaptados en portugués.

Várias dições, que tinham sido outrora daqui exportadas, ou tinham cá sinónimos mais portugueses, foram modernamente importadas no país, por escritores eruditos e dicionaristas solícitos, com trajos exóticos e burlescos, tais como: [...] shogun por xogum.

$\mathrm{Y}$ a pie de página aclara el origen del dígrafo:

E assim pensam outros escritores modernos, que não gostam de prata de casa, e perfilham ortografias que nem são tradicionais, nem scientíficas, nem etimológicas, mas sómente estrangeiras e as mais das vezes desarrazoadas. [...] Pois sch representa, na língua original, uma só letra, cuja fonação se conforma exactamente com a do nosso $x$ inicial; mas o congresso dos orientalistas (1884) optou por $s h$, que é fonema inglês, sem valor em português.

\begin{tabular}{|c|c|c|}
\hline \multicolumn{3}{|c|}{ «TAICUN»/'taikuN/ } \\
\hline 1. ${ }^{a}$ doc. textual & $\begin{array}{l}\text { Tayco } \\
\text { Tycoon } \\
\text { Taikun }\end{array}$ & $\begin{array}{l}\text { 1599: Gil (1991: 79) } \\
\text { 14/06/1860: Diario del Gobierno de la } \\
\text { República Mexicana } \\
\text { 18/07/1863: La España (Madrid) }\end{array}$ \\
\hline 1. a doc. lexicográfica & taikun & 2008: DUE \\
\hline \multicolumn{3}{|c|}{$\begin{array}{l}\text { El diccionario monolingüe Daiyirín nos informa de que en la era Edo (1603- } \\
1868)^{79} \text { este era el nombre con el que el «siogun» se designaba a sí mismo } \\
\text { de cara al extranjero }{ }^{80} \text {; por este motivo, las obras lexicográficas occidentales } \\
\text { equiparan conceptualmente los significantes «taicun» y «siogun» (DUE, } \\
\text { MWCD, OED y Zingarelli). En la Hemeroteca, la vida de este japonesismo } \\
\text { es breve: pervive desde } 1863 \text { hasta } 1933 \text {. No se utiliza en ninguno de los } \\
\text { corpus consultados (CORDE, CORDIAM, CREA y CORPES XXI). }\end{array}$} \\
\hline
\end{tabular}

trabajo: «[...] Hizo esto porque Tokio era la ciudad de los Shogon, conocidos en Europa por el nombre de Taigun, la dinastía rival que había destonado á la suya».

79 Según Gil (1991: 36), fue usado a partir de 1591.

80 De acuerdo con el OED, lo hacía con el fin de separar Japón del sistema de relaciones chino. Así, por ejemplo, leemos en la Hemeroteca: "Para lograr estos fines, y especialmente el de devolver al Mikado todo el poder que durante muchos siglos le había usurpado el Gio-gun, Iwakura, creyendo que un acto de soberanía robustecería el vacilante poder del usurpador de Yedo, se opuso con toda su influencia en 1858 á que el Gobierno del que se hacía llamar 
Sin embargo, Gil (1991: 36) explica que, en los primeros testimonios que examina, españoles y portugueses hablan de la figura del Taicosama ${ }^{81}$ (encarnada por Toiotomi Jideiosi), que no es nada más que la adaptación europea del término a la que se le ha añadido el componente de cortesía -sama. Esta misma idea sustentan los textos que recoge Dalgado (19191921). Todo apunta, por tanto, a que este japonesismo ha sufrido un proceso de poligénesis temporal en ambas lenguas ${ }^{82}$ : (1) se introdujo en la primera etapa de contactos; (2) se utilizó tras la apertura de Japón al mundo. Salvo las lenguas ibéricas que sí presentan dos etapas de introducción, en el resto de las lenguas occidentales consultadas solo existen primeras documentaciones tras la internacionalización de Japón (segunda mitad del siglo XIX): 1857 (MWCD y OED), 1894 (Zingarelli). Aunque de nuevo podrían argüirse algunas razones para defender la intermediación de la lengua francesa ${ }^{83}$, son más numerosas las causas que apoyarían la intervención del inglés en el resultado moderno:

Tai-Kun negociase tratados con las potencias occidentales" (Archivo diplomático-político de España: 21 de septiembre de 1883). Apréciese cómo se están equiparando los términos de Gio-gun (errónea transcripción de «siogun») y Tai-Kun, «taicun». Existen situaciones análogas en inglés: "Today, I am told Ziogoon [«siogun»] is not the proper appellation of their ruler, but that it is Tykoon [«taicun»]. Ziogoon is literally 'Generalissimo' while Tykoon means 'Great Ruler"' (OED: 1857), "The title of taikun (often misspelt tycoon) was then for the first time used; it was employed for the occasion by the Tokugawa officials to convey the impression that their chief was in reality the lord paramount" (OED: 1881); y también en francés: "Le Mikado approuva ce qu'il n'avait pu empêcher, et confirma Hide-Yosi dans sa dignité de siogoun, sous le nouveau nom de Taiko ou de Taiko-Sama, c'est-à-dire le seigneur Taiko" (1850 -corregimos la fecha dada por Dalgado (1854); véase explicación en nota 83-), "Primitivement, le taïcoun portait le nom de siogoun quand il commandait les urmées, et, de nos jours encore, les deux titres de siogoun et de taïcoun représentent le même souverain, mais caractérisent ce souverain exerçant les attributions militaires ou les attributions civiles" (1875: GDU XIX).

${ }^{81}$ En la obra de Gil (1991) encontramos ejemplos de Tayco, Taycosama o Taycoçama (desde 1599 hasta 1615). La primera datación para Tayco es del año 1599, mientras que Taycosama es de 1609.

82 Aunque Dalgado (1919-1921) documenta usos de Taicosama hasta 1874, el DHLP indica que la forma moderna procede de la lengua inglesa.

83 Tanto cronológicas como hegemónicas. Si bien, en la primera documentación (la obra de Dubois de Jancigny, 1850 -año que ofrece la Biblioteca Nacional de España: http://bdh. bne.es/bnesearch/CompleteSearch.do?visor $=\&$ text $=\&$ field 1 val $=\% 22$ Dubois + de + Jancigny $\%$ $2 \mathrm{c}+$ Adolphe $\% 22 \&$ show YearItems $=\&$ field $1 \mathrm{Op}=\mathrm{AND} \&$ numfields $=1 \&$ exact $=$ on\&textH $=\& \mathrm{a}$ $\mathrm{d}$ vanced $=$ true $\&$ field $1=$ autor $\&$ completeText $=\&$ pageSize $=1 \&$ pageSizeAbrv $=30 \&$ pageNumb er=2-) aportada por Dalgado (1919-1921), se emplean las formas Taiko y Taiko-Sama, las cuales claramente remiten a las primeras adaptaciones hispano-lusas. El hecho de que Colby Knowlton (1959: 717-718) documentara muestras de taïcoun, Taïgoun, taïkoun, taikounat, Taikouns, taïkounales, Taikoun, taïkounale, taikounat en francés desde 1857/8 hasta 1879 revela que hubo de producirse una nueva reintroducción, y esta pudo darse por mediación de la lengua inglesa (véanse las transcripciones menos adaptadas, esto es, sin diéresis y con 
(i) su origen inglés viene refrendado por otras obras lexicográficas (DLF, DHLP, DOVLI y Zingarelli); (ii) en comparación con las primeras representaciones gráficas, las adaptaciones decimonónicas ${ }^{84}$ hispánicas usan la grafía $k$ y el étimo original sin el componente de cortesía -sama, esto es, /tai'kun/ - al menos así debería entenderse ${ }^{85}$-; (iii) mientras que el patrón acentual del étimo es paroxítono, en lengua inglesa es oxítono (OED), y con este pasó a otras lenguas (DHLP, DOVLI y Zingarelli), entre las que se incluye la española ${ }^{86}$; (iv) la primera documentación textual hispánica de Tycoon $(1860)^{87}$ es una traducción entrecomillada de un texto inglés, tal y como se especifica al inicio: "Recepción de los embajadores japoneses en Washington. Leemos en un periódico de Washington, fecha 18 de Mayo". En el texto de la grafía adaptada, Taikun (1863) -ambos testimonios posteriores al inglés (1857)-, se está aludiendo a problemas políticos entre Japón e Inglaterra: “De la discusion sobre el Japon recientemente suscitada en el parlamento británico, resulta que el gobierno inglés está dispuesto á declarar la guerra al Tycoon si no se apresura á dar las debidas reparaciones y satisfacciones por los últimos ultrajes cometidos contra súbditos ingleses". Curiosamente, a pesar de que en el inicio del texto se emplea la forma inglesa, Tycoon, en unas líneas posteriores se utiliza la grafía Taikun ${ }^{88}$. Las relaciones políticas (principalmente conflictos bélicos) de Japón con otras superpotencias -Inglaterra y EE.UU.(Junqueras, Madrid y Martínez 2013; Hane 2015; Walker 2017) volvieron a poner de moda el término; (v) el japonesismo rápidamente cayó en el olvido y jamás fue inventariado por una obra académica (NTLLE). Sí existen casos de tycoon en la Hemeroteca, CREA y CORPES XXI, pero empleados con otro significado. En efecto, en Occidente este japonesismo desarrolló otro valor semántico:'líder (especialmente) político / magnate de los negocios / personaje potente y autoritario’ (MWCD, OED, DFL, DHLP, DOVLI, Zingarelli),

\footnotetext{
k). La voz tuvo que calar rápidamente en el sistema galo, pues el GDU XIX (tomos 9 y 14, 1872 y 1875 respectivamente) informa sobre la figura del taïcoun, incluso sobre los derivados taïcounal/e y taïcounat, todos significantes adaptados al sistema ortotipográfico de la lengua francesa. De haber seguido la propuesta enciclopédica, en lengua española habríamos registrado casos de taicun. Por último, tras conocer los datos recién expuestos, nos sorprende que no se informe sobre esta voz en el PR, el DHLF ni el Trésor.

${ }^{84}$ En el GDU XIX (tomos 9 y 14, 1872 y 1875 respectivamente) se utiliza la adaptación taïcoun.

85 Suponemos que seguirían las normas ortográficas vigentes, las de 1820. Recuérdese la regla en nota 63 .

86 La ausencia de tilde en las adaptaciones hispánicas de la época nos inclina a pensar que la voz se articulaba oxítona.

87 Los casos de Tycoon con el valor semántico etimológico se recogen en la Hemeroteca hasta 1910.

88 En el mismo texto aparecen discusion y Japon sin tilde, siguiendo los preceptos académicos de 1820, por lo que nuestra suposición sobre su patrón acentual pudiera ser cierta.
} 
representado gráficamente mediante la forma anglosajona tycoon. Según el OED, se empleó por primera vez en 1861 para aludir al presidente Abraham Lincoln. En italiano hay muestras desde 1975 (DOVLI y Zingarelli). También se emplea en portugués y francés, pero ni DHLP ni DFL ofrecen datación. En cuanto a la lengua española, la primera documentación se localiza en la Hemeroteca en $1962^{89}$ : Diario de Las Palmas (16/06/1962), y se mantiene hasta la actualidad (hallamos ejemplos en CREA, CORPES XXI y Hemeroteca). Existen pruebas que demuestran que la cultura anglosajona promovió el uso de esta voz japonesa convertida ya en anglicismo: por un lado, las novelas de C. E. Scoggins (1934) y F. Scott Fitzgerald (1941), la primera titulada Tycoon y la segunda, The Last Tycoon. Por otro lado, la influencia del cine: basada en la primera, John Wayne protagonizó una película homónima en 1947, la cual se tradujo como Hombres de presa $^{90}$ (Cf. https://www.imdb. com/title/tt0039927/); por lo que respecta a la obra póstuma de Fitzgerald, tuvo una adaptación televisiva de 1950 a 1957 (Cf. https://www.imdb.com/ title/tt0687571/?ref_=fn_al_tt_6) y una película en 1976 (Cf. https:/www. $\mathrm{imdb.com} / \mathrm{title} / \mathrm{tt} 00 \overline{\overline{7}} 477 \overline{7} /$ ? $\overline{\mathrm{ref}} \overline{-}=\mathrm{fn} \_\mathrm{al}$ _tt_2), protagonizada por Robert De Niro, Tony Curtis y Jack Nicholson, entre otros.

\section{CONCLUSIONES}

Con el propósito de que nuestras conclusiones sean lo más acertadas posibles, hemos aglutinado los datos en diferentes secciones: iniciaremos nuestra síntesis relacionando la primera documentación textual de los japonesismos con fenómenos históricos contemporáneos; este apartado, además, incluirá una descripción relativa a la poligénesis temporal de estas voces de origen japonés. En el segundo punto revisaremos cuál ha sido el tratamiento etimológico que estas unidades han recibido por parte de la Real Academia Española y ofreceremos la media de años que esta ha necesitado a la hora de incorporar, o no, tales voces. En la sección tercera trataremos sobre la mayúscula inicial en algunas de las unidades léxicas. Por último,

89 Parece ser que este anglicismo no entró en lengua española en el periodo 1860-1910 (para Tycoon) ni en 1863-1933 (Taikun), puesto que en ninguna de las muestras la voz viene empleada con este valor semántico. Corregimos la información de Fernández Mata (2018b).

90 Por ejemplo, el segundo uso de Tycoon que localizamos en la Hemeroteca es una referencia a esta película: Primer plano (Madrid): 21/12/1962. 
intentaremos dilucidar la compleja cuestión de si los japonesismos bélicogubernamentales examinados desembarcaron directamente de la lengua japonesa o de si alguna otra lengua próxima a la española actuó como intermediaria.

\subsection{Primeras documentaciones teXtuales Y FACTORES HISTÓRICO-SOCIOLÓGICOS}

La adopción de los japonesismos bélico-gubernamentales coincide precisamente con un periodo convulso de la historia nipona, el cual se inició con la restauración Meyi (1867/68-1912). Japón entró a formar parte del tablero político mundial y esto le acarreó no solo una serie de conflictos internos (abolición del sistema feudal, occidentalización, etc.), sino también internacionales (guerras con China, Rusia, Estados Unidos, etc.) (Junqueras, Madrid y Martínez 2013; Hane 2015; Walker 2017).

Grosso modo, podemos afirmar que casi la totalidad de los préstamos bélicos y gubernamentales de origen japonés se introdujeron en la lengua española en la segunda mitad del siglo XIX ${ }^{91}$ : «siogun» (1857), «micado» (1857), «taicun» (1860), «daimio» (1863), «jaraquiri» (1866), «samuray» (1874), «catana» (1885), «busido» (1904), «banzay» (1904) y «camicace» $(1937-1944-)^{92}$. Podemos comprobar que las fechas de introducción son análogas o próximas a diferentes conflictos bélicos en los que Japón fue protagonista y de los que se informa en prensa: la primera guerra sinojaponesa (1894-1895), la guerra ruso-japonesa (1904-1905), la segunda guerra sino-japonesa (1937-1945) y la Segunda Guerra Mundial (19391945).

Asimismo, al igual que Millán (2019), creemos que el papel de las crónicas de viajes fue decisivo a la hora de dar a conocer estos conceptos en Occidente. De hecho, en muchas de las narraciones analizadas de la Hemeroteca, se utiliza el exotismo oriental para, permítasenos la licencia, enganchar al lector, transportarlo a lejanas culturas. Millán (2019) examina la obra del diplomático español Francisco de Reynoso (En la Corte del Mikado. Bocetos japoneses, 1904), pero menciona, sin pretender ser exhaustivo,

\footnotetext{
91 Clasificamos cronológicamente. Si los años coinciden, tendremos en cuenta mes y día. Si estos últimos son iguales, recurrimos al orden alfabético.

92 Como ya explicamos en la sección anterior, en la documentación de 1937 el término se emplea como nombre de una aeronave. Su primer uso con el valor semántico de 'avión/ piloto suicida' se fecha en 1944.
} 
otros muchos casos de literatura de viajes al Japón -ingleses, franceses y españoles-: Hodgson (A Residence at Nagasaki and Hakodate in 1859-1860, with an Account of Japan Generally, de 1861), Lindau (Un voyage autour du Japon, de 1864), Beauvoir (Voyage autour du Monde, 1872), Bousquet (Un voyage dans l'interieur du Japon, de 1874; L'hiver au Japon, de 1874), Bird (Unbeaten Tracks in Japan, de 1880), Claparède (A travers le Japon: Notes d'un touriste, de 1882), Knollys (Sketches of Life in Japan, de 1887), Muñoz y Viñaza (Escritos de los portugueses y castellanos, referentes á las lenguas de China y el Japón: estudio bibliográfico, de 1892), Enrique Dupuy de Lôme (La transformación del Japón en la era Meiji, de 1895). No es de extrañar, por tanto, que los libros de viajes y las publicaciones periódicas se hicieran eco de los profundos cambios sociales que estaba experimentando el país del sol naciente: la derrota del «siogun» o «taicun» frente al «micado», la desaparición de los «daimios» y últimos «samuráis», que ya jamás volverían a hacerse el «jaraquiri» con sus afiladas «catanas».

En cuanto a los tres japonesismos introducidos en el siglo XX, la situación es muy similar, puesto que en sus primeros registros textuales estos vocablos se emplean en narraciones que describen la guerra ruso-japonesa (1904, «busido» y «banzay») o la Segunda Guerra Mundial (1944, «camicace»). ¿Por qué no pensar que los occidentales quedaron fascinados por la lealtad de los combatientes nipones - «camicaces» o no-, quienes, bajo el influjo de su místico código moral, «busido», se lanzaban hacia sus objetivos sin miedo a perder la vida con el grito de «banzay»? Por otro lado, Colby Knowlton (1959: 495) sostiene que la rápida expansión de la voz «busido» en Occidente le debe mucho al libro de Inazo Nitobe, titulado Bushido, el cual fue escrito en inglés (1898) y traducido a diversas lenguas. En español, se tradujo por primera vez en 1909 (Rodríguez 2007: 170-171) ${ }^{93}$.

Por último, no debemos olvidar otros factores que, si bien menos directos, también contribuyeron a la difusión y mantenimiento de estas voces: en primer lugar, la Exposición Universal de Londres en 1862 abrió las puertas al orientalismo y al japonismo ${ }^{94}$ en Occidente (Millán 2019: 13). Japón

93 Rodríguez (2007: 167) describe el contexto histórico que envolvía la publicación de dicho libro: "cuando esta obra se comenzó a traducir al castellano [...], hacía tres años que los japoneses habían vencido aplastantemente a los rusos, y que hacía una década (1895) de su "sonada" victoria en la guerra contra China, así que estas circunstancias propiciaron que el prestigio de los militares japoneses, herederos de los samuráis y del Bushido, se acrecentara a nivel internacional, y que consiguientemente la obra de Nitobe sobre este tema cobrase una inusitada actualidad".

94 Para conocer más acerca de este movimiento, vid. Fernández Mata (2016b). 
participó en la Exposición Universal de Barcelona en 1888 (Garrut 1976; Roig 1995), lo que supondría un contacto directísimo entre ambas culturas.

En lo relativo a la trayectoria de algunos préstamos en nuestra lengua, mientras que ocho unidades («banzay», «busido», «camicace», «daimio», «jaraquiri», «micado», «samuray» y «siogun») se introdujeron a lo largo de la segunda mitad del siglo XIX y primera parte del XX, observamos discontinuidad en «catana» $\mathrm{y}$ "taicun», pues ambos se registran en las postrimerías del siglo XVI e inicios del XVII. No obstante, merecen especial mención «jaraquiri», «samuray» $\mathrm{y}$ «siogun»; el primero, porque existen testimonios lusos y castellanos acerca de este ritual documentados en los siglos XVI y XVII. En ellos se describe el acto, pero no se utiliza el significante. El segundo, porque Dalgado (1919-1921) sitúa un caso de çamurai en un texto portugués de 1552 . Y el último, porque podemos ubicar muestras de «siogun» en otras lenguas europeas en épocas anteriores: portugués (1607), español (1609)95, inglés (1615), italiano (1644), francés (1715).

\subsection{INVENTARIADO EN OBRAS LEXICOGRÁFICAS Y ETIMOLOGÍA}

La RAE ha necesitado una media ${ }^{96}$ aproximada de 76 años para incorporar estos elementos en alguna de sus obras lexicográficas; «siogun» fue el que más tardó en añadirse (113 años) y «micado», el que menos (27 años).

\begin{tabular}{|c|c|c|c|}
\hline Japonesismo & $\mathbf{1 .}^{\text {a }}$ doc. text. & $\mathbf{1 .}^{\text {a }}$ doc. $\mathbf{R A E}$ & Diferencia \\
\hline «banzay» & 1904 & --- & --- \\
\hline «busido» & 1904 & 2001 & 97 años \\
\hline «camicace» & 1937 & 1992 & 55 años \\
\hline «catana» & 1885 & 1925 & 40 años \\
\hline «daimio» & 1863 & 1956 & 93 años \\
\hline «jaraquiri» & 1866 & 1970 & 104 años \\
\hline «micado» & 1857 & 1884 & 27 años \\
\hline «samuray» & 1874 & 1956 & 82 años \\
\hline
\end{tabular}

95 Recuérdese que es hipótesis nuestra. Véase descripción de «micado».

96 Para el cálculo de la media, únicamente hemos considerado las voces incluidas en los diccionarios de la RAE, esto es, ocho unidades. En cuanto a «catana», hemos seleccionado la primera documentación lexicográfica de su forma etimológica y femenina. 


\begin{tabular}{|c|c|c|c|}
\hline «siogun» & 1857 & 1970 & 113 años \\
\hline «taicun» & 1860 & --- & --- \\
\hline
\end{tabular}

De los 10 japonesismos bélico-gubernamentales, la RAE nunca ha introducido «banzay» ni «taicun»-ensombrecidos- en sus diccionarios, pese a que, como se puede comprobar en la siguiente tabla: (1) estas voces cuentan con un primer registro textual anterior al de los otros japonesismos de la misma área referencial ya incorporados; y (2), han sido descritas por otros diccionarios hispánicos importantes. Puede que la Academia las haya obviado por su uso circunstancial o prácticamente inexistente en el español de hoy.

\begin{tabular}{|c|c|c|c|c|}
\hline Japonesismo & 1. $^{\text {a doc. text. }}$ & $\begin{array}{c}\text { Uso } \\
\text { CREA }\end{array}$ & $\begin{array}{c}\text { Uso CORPES } \\
\text { XXI }\end{array}$ & $\begin{array}{c}\text { Otros } \\
\text { diccionarios }\end{array}$ \\
\hline «banzay» & 1904 & 0,01 & 0,01 & DClave \\
\hline «busido» & 1904 & 0,03 & 0,07 & No procede \\
\hline «camicace» & 1937 & 0,45 & 0,82 & No procede \\
\hline «catana» & 1885 & 0,02 & 0,12 & No procede \\
\hline «daimio» & 1863 & 0,00 & $\sin$ muestras & No procede \\
\hline «jaraquiri» & 1866 & 0,30 & 0,20 & No procede \\
\hline «micado» & 1857 & 0,06 & 0,07 & No procede \\
\hline «samuray» & 1874 & 0,70 & 1,16 & No procede \\
\hline «siogun» & 1857 & 0,13 & 0,10 & No procede \\
\hline «taicun» & 1860 & sin & sin muestras & DUE \\
\hline
\end{tabular}

Nota. El uso normalizado expresa "X casos por millón".

En lo concerniente a la etimología de las unidades sí incluidas en un diccionario académico, detectamos que: (i) de una voz solo se describe su origen japonés, sin étimo («busido», desde DLE 2001); (ii) de dos japonesismos se indica su procedencia japonesa y su étimo, aunque este no ha sido traducido («samuray», en 1956 se señaló su procedencia nipona y en DLE 2001 se incluyó el étimo; «siogun», en el suplemento de 1970 se incluyó una especie de étimo-pronunciación que se ha mantenido, con algún cambio de transcripción fonética, hasta la actualidad); (iii) el resto de los ítems léxicos examinados cuentan con étimos traducidos («catana», desde DLE 2001; «daimio», desde DLE 1956 origen japonés, pero étimo y traducción en actualización del DLE 2014; «jaraquiri», desde 1970 origen 
japonés y traducción de un étimo omitido, pero en reciente actualización del DLE 2014 se incluye étimo y traducción de sus partes; «micado», desde 1936 se informa de su étimo y la traducción de sus partes), aunque, en ocasiones, desconocemos cuál es la equivalencia exacta de los constituyentes («camicace», desde DLE 1992).

\subsection{USO DE MAYÚSCULAS PARA LOS CARGOS Y TÍTULOS DE DIGNIDADES}

Nos hemos percatado, en los corpus y Hemeroteca, que cinco japonesismos bélico-gubernamentales han sido adaptados -y todavía lo son- con mayúscula inicial; nos referimos a las unidades: «micado», «siogun», «taicun», «daimio»y «busido»" ${ }^{97}$. Dado que sus primeros testimonios se ubican entre 1857 y 1904, los usuarios de la lengua española de entonces seguirían los preceptos de la novena edición de la Ortografía de la lengua castellana (1820), la cual, en el capítulo dedicado al empleo de la mayúscula, aclara en su regla IV:

Asimismo se escribirán con mayúscula [...] los títulos ó renombres que se dan á algunas personas, como el Gran Capitan, el Filósofo, el Poeta, el Santo, el Sabio, el Prudente. Los nombres de dignidad, como Pontífice, Cardenal, Rey, Duque; y los de empleos ó cargos honoríicos, como Presidente, Corregidor, se escribirán con mayúscula solo cuando estan puestos en lugar del nombre propio de aquel que egerce dichos empleos (RAE, 1820: 74).

Si atendemos al valor semántico de los japonesismos mencionados, solo «busido» se aleja de esta norma, pues significa un tipo de ética, y tal vez, por eso mismo, se entienda como nombre propio ${ }^{98}$.

Nuestro método de transcripción no emplea la mayúscula con estos términos, puesto que sigue los preceptos de la nueva Ortografia (RAE y ASALE 2010), en la que claramente se especifica que:

los sustantivos que designan títulos nobiliarios, dignidades y cargos o empleos de cualquier rango (ya sean civiles, militares, religiosos, públicos o privados) deben escribirse con minúscula inicial por su condición de

$97 \quad$ Esto no quiere decir que el resto de voces no presenten casos aislados de mayúscula inicial. Si bien, desconocemos los motivos por los que esta se emplea.

98 En la regla III leemos: "Se han de escribir con letra mayúscula los nombres propios de personas, como Pedro, María" (RAE 1820: 73). 
nombres comunes, tanto si se trata de usos genéricos $[\ldots]$ como si se trata de menciones referidas a una persona concreta $[\ldots]$.

Aunque, por razones de solemnidad y respeto, se acostumbra a escribir con mayúscula inicial los nombres que designan cargos o títulos de cierta categoría en textos jurídicos, administrativos y protocolarios, así como en el encabezamiento de las cartas dirigidas a las personas que los ocupan u ostentan, se recomienda acomodarlos también en estos contextos a la norma general y escribirlos con minúscula (RAE y ASALE 2010: 470-471).

Por lo que respecta a «busido», entendido como una especie de corriente filosófica, se escribe con minúscula por su condición de sustantivo común (RAE y ASALE 2010: 494).

\subsection{LENGUAS INTERMEDIARIAS Y TRANSCRIPCIÓN DE LOS JAPONESISMOS}

Como también concluimos en Fernández Mata (2019d), determinar el grado de acción de otra lengua en el proceso de adopción de un préstamo es una de las cuestiones más complejas a las que nos hemos enfrentado; y no solo porque en ocasiones es posible argüir el mismo argumento (por ejemplo, el cronológico - la voz X ha sido documentada el mismo año en inglés y en francés-) para defender una postura, sino porque, a menudo, para el análisis de esta materia, no solemos contar con toda la información necesaria, lo cual nos obliga a tomar decisiones que se fundamentan en bases demasiado débiles.

Con objeto de demostrar estas afirmaciones, nos valdremos del diplomático español Reynoso. Vivió en Japón un tiempo, aprendió el idioma y para la redacción de su libro hubo de consultar numerosa bibliografía en otras lenguas (Millán 2019: 14-16). La complejidad radica en determinar si Reynoso -aplíquese a cualquier otro usuario de japonesismos- copió el significante escrito de otra lengua o si, por el contrario, utilizó un método de transcripción extranjerizante, puesto que con la primera opción podríamos afirmar que la voz X nos llegó a través de la lengua X, mientras que con la segunda no. Esto quiere decir que, siempre que un japonesismo se escriba igual en varias lenguas, a menos que el autor especifique de manera directa qué lengua ha tomado como referente a la hora de transcribir una voz en español, este acertijo histórico resulta prácticamente indescifrable. Por desgracia para el investigador, el que un usuario revele sus intenciones transcriptivas ocurre solo en el mejor de los casos. Al respecto, recordemos el ejemplo de shogun, para el que Reynoso aclara que el dígrafo $s h$ es un "sonido fonético inglés". No obstante, aunque para este japonesismo en 
concreto conozcamos de buen grado la referencia visual, ¿debemos afirmar que shogun nos vino a través de la lengua inglesa incluso a sabiendas de que Reynoso sabía hablar japonés? ¿No sería más correcto pensar que este hombre de mundo aceptó de manera explícita -para esta voz, tácita para otras- una tradición escrita ${ }^{99}$ ?

De este modo, a la intención del usuario hemos de sumar otro inconveniente: el patrón transcriptivo. ¿Una forma gráfica extranjerizante es motivo suficiente para determinar que una voz nos llegó a través de otra lengua distinta a la japonesa? Llegados a este punto, es necesario delimitar cuándo consideraremos la actuación de una lengua intermediaria. Desde nuestro punto de vista, una lengua distinta a la japonesa actuaría en el proceso de adopción siempre que: (i) el usuario de lengua española la hubiera oído en boca de tales hablantes -verbigracia, hablantes de inglés-; (ii) el usuario de lengua española la hubiera visto escrita en tales textos - verbigracia, obras en inglés-. Es obvio que en el caso de Reynoso se da la segunda condición ${ }^{100}$, porque era conocedor de otras crónicas de viajes elaboradas en el XIX por escritores extranjeros, pero también es cierto que el diplomático tuvo contacto directo con hablantes nativos japoneses. Reynoso, pues, nos sirve como claro exponente del problema que el investigador de japonesismos debe afrontar. Recordemos sus palabras:

Para facilitar la lectura de los nombres japoneses, de personas, cosas y lugares, contenidos en este libro, se ha tratado de armonizar, en lo posible, la pronunciación japonesa, con la ortografía castellana, tratando al mismo tiempo, de no alterar la estructura de las palabras, tal y como las escriben la mayoría de los autores occidentales que han publicado obras sobre el Japón en los últimos años, á fin de evitar la confusión que resultaría, de construirlas de modo diferente del usual y admitido, tanto en Europa como en América (Reynoso 1904: XI).

A nuestro entender, armonizar las voces de origen japonés a la ortotipografía española y respetar el componente visual producto de la tradición escrita dan como resultado una sustancia tóxica que envenena las condiciones de cualquier pesquisa. La suerte nos sonríe en el caso de Reynoso, pero, repetimos, se trata de una situación excepcional. En la Hemeroteca hemos encontrado algunas muestras en las que se mencionaba de manera explícita que el texto era traducción al español de documentos franceses o ingleses,

99 De hecho, el propio autor lo precisa. Véase la cita que incluimos más abajo: Reynoso (1904: XI).

100 Asimismo, podría haber oído japonesismos pronunciados por hablantes de otras lenguas. 
aunque, insistimos, son ejemplos inusuales. Lamentablemente, no podemos preguntar a todos los usuarios sus intenciones gráficas ni sus fuentes.

Lo que sí nos queda claro, después de revisar toda la documentación que hemos empleado en la redacción de este artículo, es que existía una tradición europea y americana para adaptar las voces japonesas en la que los pueblos hispánicos - podríamos hacerlo extensible también a lusos e italianos- no participamos ${ }^{101}$. Ese acuerdo implícito dio lugar a que voces como «catana», que en el periodo de primeros contactos (siglos XVI y XVII) se transcribía a la española, esto es, catana, contara con significantes exóticos a inicios del XX: katana. Determinar qué lenguas contribuyeron con sus grafemas a la creación de este sistema de occidentalización requeriría de un análisis profundo, probablemente una tesis o la colaboración de diferentes equipos científicos. Dada la cercanía o similitud de muchos de los grafemas aglutinados por dicho método a lo largo del tiempo con los empleados en inglés, nos aventuraríamos a afirmar que el peso de esta lengua en la tradición fue muy importante - si bien, esto está por demostrar ${ }^{102}$-. Los diversos hábitos de escritura se fueron unificando durante el siglo XIX y terminaron por cristalizar en el sistema de transcripción Hepburn (1886), que desde entonces comenzó a ganar terreno: es el sistema preferido en diccionarios (bilingües), enciclopedias y monografías sobre Japón, artículos de revistas informativas, textos romanizados dirigidos a docentes y estudiantes de japonés como segunda lengua, y en la adaptación de nombres propios (Rodríguez-Izquierdo 1991: 124-125; Seeley 2000: 138-151; Prieto 2007: 181; Vance 2008: 239-244; Gottlieb 2010: 75-78).

Por otro lado, y para rizar el rizo de la complejidad, el que en un primer registro textual se especifique que la voz procede de una traducción no

101 Recuérdense las palabras de Reynoso (1904: XI) o de Dalgado (1919-1921: XIX) que citamos en la descripción histórica de «siogun». Por otro lado, una letra tan importante en los "asuntos japoneses" (vid. Salvador y Lodares 2008: 150) como $k$, en gran parte del periodo (de 1815 a 1869) en el que se estaba gestando este método de occidentalización de vocablos japoneses, "desapareció del diccionario académico y, por lo mismo, de otros muchos que se inspiraban en él" (Salvador y Lodares 2008: 143). Además, en el prefacio de la primera edición del diccionario de Hepburn (1867), el autor expresa claramente que se ha basado en los sonidos del inglés y en la manera en que los estudiantes de japonés -inferimos que en su mayoría eran norteamericanos-se aproximan a dicho idioma: "and the system of orthography, with a few variations, is that generally adopted by the students of the language in Japan".

102 En la comparación que Millán (2019) realiza entre la obra de Reynoso y otras escritas en inglés y en francés en el XIX, el investigador llega a la conclusión de que "el inglés presenta formas muy parecidas al actual sistema de romanización Hepburn", mientras que en francés aprecia "una enorme variedad de criterios entre unos autores y otros, fruto de intentos diversos de representar los sonidos japoneses en esa lengua” (Millán 2019: 16). 
nos da la potestad para determinar que tal japonesismo nos llegó por una lengua. Bajo nuestro punto de vista, deberíamos poner en cuarentena aquellos testimonios que sostienen que la intención de la primera muestra vale para todas. Es insuficiente el significante visual de un solo usuario, necesitamos el conjunto de la comunidad; pero, iy si seis usuarios se basaron en transcripciones inglesas, cuatro en adaptaciones francesas y el resto simplemente seguían una tradición escrita, sintetizada, por ejemplo, en la idea de que kamikaze debe escribirse con $k$ por tener este grafema un valor exótico ${ }^{103}$ ?

Tras estas reflexiones, llegamos a la realista conclusión de que tratar de conocer de manera exacta la mediación de una lengua en el proceso de adopción de un japonesismo se ha convertido en un problema de difícil solución. Por este motivo, antes de presentar nuestros resultados de manera concisa, quisiéramos advertir, en primer lugar, que quizá futuras búsquedas pudieran completar ciertos huecos informativos de nuestro rompecabezas o hacer que las piezas encajen de diferente manera, $y$, en segundo lugar, que a lo largo de nuestro texto podrían tomarse como elementos sinónimos el concepto de patrón/grafía extranjerizante y el sistema de occidentalización Hepburn (1886), dado que el segundo surgió como resultado del primero, cuya trayectoria hemos de situarla principalmente en el siglo XIX.

Los datos demostrarían que cinco unidades nos llegaron a través de la lengua inglesa:

\begin{tabular}{|l|l|}
\hline Japonesismo & \multicolumn{1}{|c|}{ Pruebas } \\
\hline \multirow{3}{*}{ «banzay» } & $\begin{array}{l}\text { 1.- Documentación inglesa (1893) anterior a la española } \\
\text { (1904). }\end{array}$ \\
& $\begin{array}{l}\text { 2.- Combinación morfológica cries of banzai (1893) } \\
\text { registrada previamente a la análoga hispánica (1914). } \\
\text { 3.- Ortográficamente, el español de la época no toleraba - } a i^{104} \\
\text { a final de palabra, sino -ay. }\end{array}$ \\
\hline
\end{tabular}

103 Vid. Salvador y Lodares (2008: 146): "La $k$ ha tenido su particular calvario en la ortografía española durante siglos: inútil, extranjera, antipática, fea, complicada; ha padecido los vaivenes de toda opinión humana". En una de nuestras recientes conferencias, algunos de los asistentes recriminaron que nuestro sistema de transcripción violaba la tradición escrita para algunas voces. Sin embargo, seguimos pensando que un método de adaptación a nuestra ortotipografía resulta muy necesario para evitar, por ejemplo, el uso de dobletes e incluso tripletes gráficos (aspecto que ya hemos tratado en todos nuestros trabajos).

104 En el sistema Hepburn, el diptongo japonés /ai/ se representa mediante ai: "ai has the sound of ai in aisle or eye" (Hepburn 1867); "ai has the sound of ai in aisle, or like eye" (Hepburn 1886). 


\begin{tabular}{|c|c|}
\hline «busido» & $\begin{array}{l}\text { 1.- Documentación inglesa (1898) anterior a la española } \\
\text { (1904). } \\
\text { 2.- Elemento cultural que propició su conocimiento a lo largo } \\
\text { de Occidente: el libro escrito en inglés de Nitobe, titulado } \\
\text { Bushido (1898). } \\
\text { 3.- Dígrafo inglés sh, usado en Hepburn }(1867,1886) \text {. } \\
\text { 4.- En inglés se respetó el étimo esdrújulo, aunque en español } \\
\text { la voz es llana: ¿pudo ser porque esta se leía de textos ingleses } \\
\text { y se desconocía su articulación japonesa? }\end{array}$ \\
\hline «camicace» & $\begin{array}{l}\text { 1.- Grafías que podrían seguir el sistema Hepburn (1867, } \\
\text { 1886): kamikaze. } \\
\text { 2.- Elemento cultural que propició su conocimiento a lo largo } \\
\text { de Occidente: la guerra entre Japón y Estados Unidos. }\end{array}$ \\
\hline «daimio» & $\begin{array}{l}\text { 1.- Documentación inglesa (1727) anterior a la francesa } \\
\text { (1822) y española (1857). } \\
\text { 2.- El sistema Hepburn transcribe [mjo] japonés como myo } \\
(1886) \text {. }\end{array}$ \\
\hline «siogun» & $\begin{array}{l}\text { 1.- Documentación inglesa (1615 en la época de primeros } \\
\text { contactos; } 1875 \text { tras la apertura de Japón, OED) anterior a la } \\
\text { española (1904). } \\
\text { 2.- Dígrafo inglés sh, usado en Hepburn }(1867,1886) \text {. } \\
\text { 3.- Testimonios de Reynoso (1904) y Dalgado (1919-1921). }\end{array}$ \\
\hline «taicun» & $\begin{array}{l}\text { 1.- Documentación inglesa (1857) anterior a la española } \\
\text { (1860). } \\
\text { 2.- La primera documentación hispánica procede de un texto } \\
\text { escrito en inglés. } \\
\text { 3.- Elemento cultural que propició su conocimiento a lo largo } \\
\text { de Occidente: problemas políticos entre Japón e Inglaterra. } \\
\text { 4.- Nueva acepción semántica en inglés, con forma adaptada, } \\
\text { tycoon, que pasó a otras lenguas occidentales gracias a } \\
\text { novelas y películas realizadas en inglés. } \\
\text { 5.- Varias obras lexicográficas apoyan esta teoría (DLF, } \\
\text { DHLP, DOVLI y Zingarelli). } \\
\text { 6.- En los primeros contactos, los hispanohablantes } \\
\text { emplearon fórmulas como Tayco o Taycosama, en las } \\
\text { adaptaciones decimonónicas se utiliza Taikun. }\end{array}$ \\
\hline
\end{tabular}


En cambio, podemos probar que tres japonesismos nos llegaron por mediación de la lengua francesa:

\begin{tabular}{|l|l|}
\hline Japonesismo & \multicolumn{1}{|c|}{ Pruebas } \\
\hline \multirow{5}{*}{ «jaraquiri» } & $\begin{array}{l}\text { 1.- Documentación francesa (1854) anterior a la española } \\
\text { (1866). } \\
\text { 2.- Imitación de formas francesas: uso de guion y adaptaciones } \\
\text { erróneas (harra-kiri y Kara-Kiri) posteriores a las francesas. } \\
\text { 3.- Casi todas las muestras decimonónicas del OED } \\
\text { transcriben hari-kari, por lo que esta lengua no pudo ejercer } \\
\text { influencia alguna. } \\
\text { 4.- Elementos culturales que propiciaron su conocimiento } \\
\text { a lo largo de Occidente: poder hegemónico del francés; el } \\
\text { GDU XIX dedicaba casi una columna a explicar este ritual. }\end{array}$ \\
\hline \multirow{5}{*}{ «micado» } & $\begin{array}{l}\text { 1.- Documentación francesa (1803) anterior a la inglesa } \\
\text { (1845) y española (1857). } \\
\text { 2.- Elementos culturales que propiciaron su conocimiento } \\
\text { a lo largo de Occidente: poder hegemónico del francés; el } \\
\text { GDU XIX lo describe. }\end{array}$ \\
\hline \multirow{5}{*}{ «samuray» } \\
$\begin{array}{l}\text { 1.- Documentación francesa (1852) anterior a la española } \\
\text { (1874). } \\
\text { 2.- Elementos culturales que propiciaron su conocimiento } \\
\text { a lo largo de Occidente: poder hegemónico del francés; } \\
\text { literatura francesa. } \\
\text { 3.- Por la transcripción ou y la tilde en í, el significante } \\
\text { decimonónico luso, samouraís (de 1874), parece derivar } \\
\text { del francés samouraï. Igual pudo suceder con los casos } \\
\text { hispánicos que encontramos en la Hemeroteca (desde 1876) } \\
\text { de samourai(s). }\end{array}$ \\
\hline
\end{tabular}

Por último, no creemos que en la implantación del japonesismo «catana» interviniera una lengua extranjera. A este respecto, hemos de recordar que dicho vocablo contaba con una tradición lexicográfica hispánica, que se había iniciado en el Diccionario de autoridades (1729), pese a su significante masculino; la forma femenina se introdujo con el suplemento de Domínguez en 1853. Tanto unas como otras eran transcritas con $c$, por lo que la $k$ de los testimonios fechados después de la apertura de Japón pudo deberse al influjo de la tradición europeo-americana o del sistema Hepburn. 


\section{REFERENCIAS BIBLIOGRÁFICAS}

Academia Mexicana de la Lengua. 2017. Corpus diacrónico y diatópico del español de América. [en línea]. Disponible en www.cordiam.org [Consulta 20/02/2020].

Almarza, Nieves (coord.). 2012. Diccionario Clave: diccionario de uso del español actual. Madrid: S.M. [en línea]. Disponible en http://clave.smdiccionarios.com/app.php [Consulta 20/02/2020].

Alvar Ezquerra, Manuel (coord.). 1994. Diccionario de voces de uso actual. Madrid: Arco/Libros.

Álvarez de Miranda, Pedro. 2004. El léxico español, desde el siglo XVIII hasta hoy. En Rafael Cano Aguilar (coord.). Historia de la lengua española, pp. 1037-1064. Barcelona: Aguilar.

AsAKAWA, KAN'ICHI. 1903. The early institutional life of Japan: a study in the reform of 645 A.D. Tokyo: Shueisha. [en línea]. Disponible en https://archive.org/details/ cu31924023233947/page/n47/mode/2up [Consulta 20/02/2020].

ATILF, Analyse et traitement informatique de la langue française; CNRS, Centre national de la recherche scientifique; Universidad de Lorraine. 2002. TLFi: Trésor de la langue française informatisé. [en línea]. Disponible en http://www.atilf.fr/tlfi [Consulta 20/02/2020].

Axell, Albert y Hideaki Kase. 2005. Kamikazes. Los pilotos suicidas japoneses en la Segunda Guerra Mundial. Madrid: La Esfera de los Libros.

Cannella, Mario y Beata Lazzarini (coords.). 2014. Lo Zingarelli 2015: Vocabolario della lingua italiana. Bolonia: Zanichelli. [en línea]. Disponible en http://dizionari.zanichellipro. it/ [Consulta 20/02/2020].

Colby Knowlton, Edgar. 1959. Words of Chinese, Japanese, and Korean origin in the Romance Languages. Tesis. Stanford, EE. UU.: Universidad de Stanford.

Corominas, JoAn y José Antonio Pascual. 2012. Diccionario crítico etimológico castellano e hispánico. Madrid: Gredos. CD-ROM.

Cortelazzo, Manlio y Paolo Zolli (coords.). 1990. Dizionario etimologico della lingua italiana. Bolonia: Zanichelli.

Dalgado, Sebastião Rodolfo. 1919-1921. Glossário luso-asiático. Vols. 1 y 2. Coímbra: Imprensa da Universidade.

Devoto, Giacomo y Gian CARLo Oli (coords.). 2012. Il Devoto-Oli: vocabolario della lingua italiana 2013. Florencia: Le Monnier. CD-ROM.

Fernández Mata, RAFAel. 2015a. Estudio histórico del doblete catán-catana en lengua española. Revista de Lexicografía 21: 17-30. [en línea]. Disponible en https://ruc.udc.es/ dspace/bitstream/handle/2183/22511/RL_21_2015_art_2.pdf? sequence=3\&isAllowed=y [Consulta 20/02/2020].

2015b. Los japonesismos de la lengua española: Historia y transcripción. Tesis doctoral. Sevilla: Universidad Pablo de Olavide.

2016a. El tratamiento etimológico de los japonesismos en los diccionarios del español actual. Hesperia: Anuario de filología hispánica 19 (1): 28-44. [en línea]. Disponible en https://revistas.webs.uvigo.es/index.php/AFH/article/view/694 [Consulta 20/02/2020].

2016b. Etiqueta para denominar los préstamos léxicos de la lengua japonesa: japonesismos. Español Actual 105: 55-69.

2017. Los japonesismos del español actual. Revista de Filología de la Universidad de La Laguna 35: 149-168. [en línea]. Disponible en https://riull.ull.es/xmlui/handle/915/4665 [Consulta 20/02/2020]. 
2018a. Los japonesismos marciales y deportivos. Revista de Filología de la Universidad de La Laguna 37: 61-99. [en línea]. Disponible en https://riull.ull.es/xmlui/ handle/915/8671 [Consulta 20/02/2020].

2018b. Los japonesismos bélicos y gubernamentales. Anuario de Letras. Lingüistica y Filología 6 (1): 75-118. [en línea]. Disponible en https://revistas-filologicas.unam.mx/ anuario-letras/index.php/al/article/view/1478 [Consulta 20/02/2020].

2018c. Método de transcripción del japonés al español: sonidos vocálicos, semivocálicos y consonánticos. Onomázein: Revista de lingüística, filología y traducción de la Pontificia Universidad Católica de Chile 42: 237-276. [en línea]. Disponible en http://onomazein.letras.uc.cl/04_NumeroDescarga/n42/Descarga42_7.html [Consulta 20/02/2020].

2019a. Los japonesismos culinarios. Anuario de Letras. Lingüistica y Filología 7 (1): 61-103. [en línea]. Disponible en https://revistas-filologicas.unam.mx/anuario-letras/ index.php/al/article/view/1530/1875 [Consulta 20/02/2020].

2019b. Estudio histórico de quimón, quimono y quimona en lengua española. Estudios Filológicos 63: 181-210. [en línea]. Disponible en http://revistas.uach.cl/index. php/efilolo/article/view/5591 [Consulta 20/02/2020].

2019c. Los japonesismos de la vivienda y el mobiliario en el español actual. Dicenda. Estudios de Lengua y Literatura Españolas 37: 255-273. [en línea]. Disponible en https:// revistas.ucm.es/index.php/DICE/article/view/65003 [Consulta 20/02/2020].

2019d. Análisis histórico y primeras documentaciones de los japonesismos marcialdeportivos y culinarios utilizados en español actual. En Florencio Barrio de la Rosa (coord.) Estudios de lexicología española. Lexicalización, léxico y lexicografía en la historia del español, pp. 235-278. Venecia: Ca'Foscari.

2020a. Estudio sincrónico e histórico de la locución a lo bonzo. En proceso de revisión por partes.

2020b. Estudio sincrónico e histórico de la locución verbal hacerse el jaraquiri. Revista de Investigación Lingüistica. Aceptado. En prensa.

Frago Gracia, Juan Antonio. 1997. Japonesismos entre Acapulco y Sevilla: sobre biombo, catana y maque. Boletín de Filología de la Universidad de Chile XXXVI: 101-118. [en línea]. Disponible en http://www.boletinfilologia.uchile.cl/index.php/BDF/article/ viewFile/21491/22788 [Consulta 20/02/2020].

Frellesvig, BJarke. 2010. A History of the Japanese Language. Cambridge: Cambridge University Press.

Fróis, Luís. 1981. Historia de Japam (1. a ed.). Edición anotada por José Wicki. Lisboa: Biblioteca Nacional. [en línea]. Disponible en https://books.google.es/books?id=kMZXav pL7YC\&pg=PA267\&lpg=PA267\&dq =fazer + o+harakiri\&source $=$ bl\&ots $=$ XJynk1GEV 1\&sig=ACfU3U0MZxBgAihVGTR6_dYKZ8e93uZPpw\&hl=es\&sa=X\&ved=2ahUKE wiHromu4v3mAhVPXhoKHU4rBeEQ6AEwCHoECAgQAQ\# $\mathrm{v}=$ onepage \&q\&f=false [Consulta 20/02/2020].

Garrut, Josep Maria. 1976. L'Exposició Universal de Barcelona de 1888. Barcelona: Ajuntament de Barcelona, Delegació de Cultura.

GiL, JuAn. 1991. Hidalgos y samurais. España y Japón en los siglos XVI y XVII. Madrid: Alianza Editorial.

Gómez Capuz, Juan. 2004. Préstamos del español: lengua y sociedad. Madrid: Arco Libros.

Gottlieb, Nanette. 2010. The Rōmaji movement in Japan. Journal of the Royal Asiatic Society 20 (1): 75-88.

Guerrero Ramos, Gloria. 1995. Neologismos en el español actual. Madrid: Arco Libros. Hane, Mikiso. 2015. Breve historia de Japón. Madrid: Alianza Editorial. 
Hepburn, James Curtis. 1867. A Japanese and English Dictionary: with an English and Japanese Index. Shanghái: American Presbyterian Mission Press. [en línea]. Disponible en http://www.ab.cyberhome.ne.jp/ kaizu/roomazi/doc/hep1.html [Consulta 20/02/2020]. 1886. A Japanese-English and English-Japanese Dictionary. Tokyo, Z. P. MARUYA \& Co. LIMITED. [en línea]. Disponible en http://www.ab.cyberhome.ne.jp/ kaizu/ roomazi/doc/hep3.html [Consulta 20/02/2020].

Hill, Peter. 2006. KamiKaze, 1943-45. En Diego Gambetta (coord.). Making Sense of Suicide Missions, pp. 1-42. Oxford: Oxford University Press. [en línea]. Disponible en https:// books.google.es/books?hl=es\&lr=\&id=xbU_b7y5TqkC\&oi=fnd\&pg=PA1\&dq=Peter + Hill+Kamikaze\&ots=zMW0FsZBF4\&sig $=$ YcZticlKWSa-eFO08QuLr_k2pPE\&redir_ esc $=\mathrm{y} \# \mathrm{v}=$ twopage $\& \mathrm{q} \& \mathrm{f}=$ false [Consulta 20/02/2020].

HouAiss, ANTôNio (coord.). 2001. Dicionário Houaiss da Língua Portuguesa. Río de Janeiro: Editora Objectiva.

Jeuge-Maynart, Isabelle (coord.). 2019. Dictionnaire de français Larousse. París: Hachette Livre - Département Informatique Groupe Livre (DSI). [en línea]. Disponible en https:// www.larousse.fr/dictionnaires/francais-monolingue/ [Consulta 20/02/2020].

Junqueras i Vies, Oriol, Dani Madrid i Morales y Guillermo Martínez TABerner. 2013. Historia de Japón: economía, política y sociedad. Barcelona: Editorial UOC.

KaempFer, Engelbert. 1712. Amoenitates Exoticae. [en línea]. Disponible en https://books. google.es/books?id=Xp5Zy0O01I0C\&redir_esc=y [Consulta 20/02/2020].

1727. The History of Japan, together with a description of the Kingdom of Siam. Traducción J. C. Scheuchzer. Londres: Woodward.

Lahuerta Galán, JaVier (coord.). 2003. Diccionario de uso del español de América y España. Barcelona: Vox. CD-ROM.

LAPESA, RAFAEL. 2005. Historia de la lengua española. Madrid: Gredos.

Larousse, Pierre (dir.). 1866-1888. Grand Dictionnaire universel du XIXe siècle. París: Administration du Grand Dictionnaire Universel. [en línea]. Disponible en https://gallica. bnf.fr/ark:/12148/bpt6k2053614/f1.image.r=.langFR (tomo 9, 1872), https://gallica.bnf.fr/ ark:/12148/bpt6k205363w.r=.langFR (tomo 11, 1874) y https://gallica.bnf.fr/ark:/12148/ bpt6k398019.r=.langFR (tomo 14, 1875) [Consulta 20/02/2020].

Matsumura, Akira (coord.). 2006. Daiyirín. Tokyo: Shanseido Books. [en línea]. Disponible en www.kotobank.jp [Consulta 20/02/2020].

Millán Martín, Alberto. 2019. Los japonesismos de «En la Corte del Mikado» (1904) del diplomático español Francisco de Reynoso: análisis gráfico-fonológico y morfosintáctico. Cuadernos CANELA 30: 13-35. [en línea]. Disponible en http://cuadernoscanela.org/ index.php/cuadernos/article/view/168 [Consulta 20/02/2020].

Moliner, María. 2008. Diccionario de uso del español. Madrid: Gredos. CD-ROM basado en la 3. edición en papel de 2007.

Morga, Antonio De. 1609. Sucesos de las islas Filipinas. México. [en línea]. Disponible en https://archive.org/stream/ahz9387.0001.001.umich.edu\#page/XXIV/mode/2up [Consulta 20/02/2020].

Ortega Arjonilla, Emilio. 2011. El francés de las humanidades y su traducción al español: calcos, préstamos, xenismos y adaptaciones. Anales de filología francesa 19: 235-253. [en línea]. Disponible en https://revistas.um.es/analesff/issue/view/11141 [Consulta 20/02/2020].

Priberam Informática, S.A. (ed.). 2008-2013. Dicionário Priberam da Língua Portuguesa [en línea]. Disponible em http://www.priberam.pt/dlpo/ [Consulta 20/02/2020]. 
Prieto Vera, Luis. 2007. Voces de origen japonés en el léxico de la prensa de Santiago de Chile. Boletín de Filología 42: 157-318. [en línea]. Disponible en https://boletinfilologia. uchile.cl/index.php/BDF/article/view/20826/22012 [Consulta 20/02/2020].

Quilis, ANTonio. 2006. Tratado de fonología y fonética españolas. Madrid: Gredos.

Real Academia Española. 1820. Ortografia de la lengua castellana. [en línea]. Disponible en https://books.google.es/books/about/Ortograf\%C3\%ADa_de_la_lengua_castellana. $\mathrm{html}$ id $=$ UicSAAAAIAAJ\&redir_esc $=$ y [Consulta 20/02/2020].

2001. Diccionario de la lengua española. Madrid: Espasa Calpe. [en línea]. Disponible en http://lema.rae.es/drae2001/ [Consulta 20/02/2020].

Real Academia Española y Asociación de Academias de la Lengua Española. 2009. Nueva gramática de la lengua española. Morfología. Sintaxis. Madrid: Espasa. .2010. Ortografía de la lengua española. Madrid: Espasa.

2011. Nueva gramática de la lengua española. Fonética y fonología. Madrid: Espasa.

ALE. 2014. Diccionario de la lengua española. Madrid: Real Academia Española. [en línea]. Disponible en http://www.rae.es/ [Consulta 20/02/2020].

Real Academia Española. 2020. Corpus de referencia del español actual. Banco de datos (CREA). [en línea]. Disponible en http://www.rae.es/ [Consulta 20/02/2020].

2020. Corpus diacrónico del español. Banco de datos (CORDE). [en línea]. Disponible en http://www.rae.es/ [Consulta 20/02/2020].

2020. Corpus del español del siglo XXI. Banco de datos (CORPES XXI). [en línea].

Disponible en http://www.rae.es/ [Consulta 20/02/2020].

2020. Nuevo tesoro lexicográfico de la lengua española. [en línea]. Disponible en http://www.rae.es/ [Consulta 20/02/2020].

ReY, Alain (coord.). 2014. Le Petit Robert de la langue française. París: Le Robert. CD-ROM. (dir.). 2000. Dictionnaire historique de la langue française. París: Le Robert.

ReYNoso, Francisco DE. 1904. En la Corte del Mikado. Madrid: Imprenta de Bailly-Bailliere e Hijos. [en línea]. Disponible en https://archive.org/details/enlacortedelmik00reyngoog/ page/n8/mode/2up [Consulta 20/02/2020].

Rodríguez Navarro, María Teresa. 2007. Análisis de la obra: Bushido. The Soul of Japan. De Inazo Nitobe, desde la triple perspectiva traductológica, cultural y jurídica. Tesis doctoral. Granada: Universidad de Granada.

Rodríguez-Izquierdo y Gavala, Fernando. 1991. Sobre los sistemas de Transliteración alfabética del japonés, y sus posibles adaptaciones destinadas a hispanohablantes. Boletín de la Asociación Española de Orientalistas 27: 121-130.

Roig, Josep Lluís. (1995): Historia de Barcelona. Barcelona: Primera Plana, S.A.

SAlVAdor, Gregorio y JuAn Ramón Lodares. 2008. Historia de las letras. Madrid: Espasa Calpe.

SáncheZ, AQuilino (coord.). 2006. Gran diccionario de uso del español actual. Madrid: SGEL. CD-ROM.

Seco, Manuel, Olimpia Andrés y Gabino Ramos. 1999. Diccionario del español actual. Madrid: Aguilar.

Seeley, Christopher. 2000. A history of writing in Japan. University of Hawai'i Press.

Simpson, John (coord.). 2009. Oxford English dictionary. Oxford University Press. CDROM, 2. ${ }^{\text {a ed. } 4.0 .}$

The Merriam-Webster. 2003. Merriam-Webster 's Collegiate Dictionary. 11. a ed. Springfield: Merriam-Webster. CD-ROM. 
Universidad de Aveiro y Centro de Lingüística de la Universidad de Lisboa. 2019. Corpus Lexicográfico do Português. [en línea]. Disponible en http://clp.dlc.ua.pt/Inicio. aspx [Consulta 20/02/2020].

Vance, Timothy J. 2008. The Sounds of Japanese. Cambridge: Cambridge University Press. Walker, Brett L. 2017. Historia de Japón. Madrid: Ediciones Akal. 